\title{
The 3D Structure of Northern Hemisphere Blocking Events: Climatology, Role of Moisture, and Response to Climate Change
}

\author{
Ebrahim Nabizadeh, Sandro W. Lubis, and Pedram Hassanzadeh* \\ Rice University, Houston, Texas, USA
}

\begin{abstract}
We present a comprehensive composite analysis of the 3D structure of blocks and its response to future climate change over North Pacific, North Atlantic, and Russia in summers and winters. Using reanalysis and two large-ensemble datasets from CESM1 and GFDL-CM3, we investigate the following: The climatology of 3D structure, physical processes governing the temperature anomaly associated with blocks, ability of GCMs to reproduce the 3D structure, and its response to RCP8.5. In reanalysis, over both ocean and land, the anomalous winds are equivalent-barotropic in the troposphere and stratosphere, and temperature anomalies are positive throughout the troposphere and negative in the lower stratosphere. The main seasonal and regional differences are that blocks are larger/stronger in winters, and over oceans, the temperature anomaly is shifted westward due to latent heating. Analyzing the temperature tendency equation shows that in all three sectors, adiabatic warming due to subsidence is the main driver of the positive temperature anomaly; however, depending on season and region, meridional thermal advection and latent heating might have leading-order contributions too. Both GCMs are found to reproduce the climatological 3D structure remarkably well, but sometimes disagree on future changes. Overall, the future summertime response is weakening of all fields (except for specific humidity), although the impact on near-surface temperature is not necessarily weakened; e.g., the blocking-driven near-surface warming over Russia intensifies. The wintertime response is strengthening of all fields, except for temperature in some cases. Responses of geopotential height and temperature are shifted westward in winters, most likely due to latent heating.
\end{abstract}

\section{Introduction}

Blocking events are large-scale, quasi-stationary, highpressure (anticyclonic) anomalous systems that last beyond the synoptic time scales (sometimes for weeks) and block or divert the midlatitude westerlies (Rex 1950; Green 1977; Hoskins and James 2014; Woollings et al. 2018). Due to their persistence and size, depending on the season and the region, blocking events can cause, or contribute to, various types of extreme events such as heat waves, cold spells, droughts, and heavy rainfall episodes (e.g., Barriopedro et al. 2011; Dole et al. 2011; Pfahl and Wernli 2012; Brunner et al. 2017, 2018; Schaller et al. 2018; Zschenderlein et al. 2019; Röthlisberger and Martius 2019; Wehrli et al. 2019; Lenggenhager et al. 2019; Chan et al. 2019). Despite much effort, the dynamical mechanisms responsible for the generation and maintenance of the blocking events are still not well understood (Hoskins and James 2014; Hassanzadeh and Kuang 2015; Nakamura and Huang 2018; Woollings et al. 2018). For example, while past studies have often considered blocking dynamics to be dominantly governed by dry processes, most notably through eddyblocking feedbacks (e.g., Shutts 1983; Illari and Marshall 1983; Nakamura et al. 1997; Cash and Lee 2000; Yamazaki and Itoh 2013; Luo et al. 2019), a few recent studies have used Lagrangian trajectory tracking and shown a leading-

${ }^{*}$ Corresponding author: Pedram Hassanzadeh, pedram@ @rice.edu order contribution from latent heating to blocking dynamics in some cases (Pfahl et al. 2015; Steinfeld and Pfahl 2019; Steinfeld et al. 2020).

There has been extensive research in the past two decades on how blocking events might change as the climate warms (Woollings et al. 2018). Most studies have focused on effects of climate change on the frequency of the blocking events and the corresponding weather extremes (e.g., Wiedenmann et al. 2002; Barnes et al. 2014; Hassanzadeh et al. 2014; Barnes and Polvani 2015; Horton et al. 2015; Kennedy et al. 2016; Peings et al. 2017; Coumou et al. 2018; Patterson et al. 2019; Narinesingh et al. 2020; Davini and D'Andrea 2020), while a few studies have investigated the effects on the average duration of blocking events (Barnes et al. 2012; Huguenin et al. 2020; Narinesingh et al. 2020) or their size, i.e., spatial extent (Nabizadeh et al. 2019).

Another aspect of blocking events that needs to be studied to better understand their dynamics and impacts (e.g., on surface weather) is their three-dimensional (3D) structure. Blocking events are often identified and examined on a single level (e.g., at $500 \mathrm{hPa}$ or near the tropopause) with their signature in the surface temperature sometimes considered as well. A few case studies analyzed blocking events on more than one level and found equivalentbarotropic structures throughout the troposphere (Green 1977; Tsou and Smith 1990; Mak 1991; Lupo and Smith 
1995; Ma and San Liang 2017). Using several reanalysis datasets and one decade of global positioning system (GPS) radio occultation data, Brunner and Steiner (2017) studied, among other things, the vertical structure of composited temperature $(T)$ and relative specific humidity $(S P)$ of winter and summer blocking events over three ocean basins: the North Atlantic, North Pacific, and Eastern Pacific (Southern Hemisphere). They found relatively height-independent anomalous positive $T$ structures in the troposphere, with a reversal to negative anomaly above the tropopause, which was also reported by Green (1977) in his case study. Brunner and Steiner (2017) found a more complex 3D structure for $S P$ (discussed later).

Motivated by understanding the dynamics of blockingdriven heat waves and their future changes, some studies have investigated the physics of the positive temperature anomaly throughout the troposphere and/or near the surface (e.g., Bieli et al. 2015; Kennedy et al. 2016; Wehrli et al. 2019; Zschenderlein et al. 2019, 2020). For example, Zschenderlein et al. (2019) used Lagrangian trajectory analysis and Eulerian calculations of horizontal temperature advection to quantify the role of different physical processes in European heat waves. They found that temperature increases adiabatically due to the subsidence of air throughout the troposphere with negligible contribution from horizontal thermal advection, and that diabatic heating intensifies the amplitude of this increase just near the surface, where vertical advection is negligible.

Building on the aforementioned studies and motivated by questions about the dynamics and impacts of blocking events in a changing climate, in this paper, we present a comprehensive analysis of the climatology of the 3D structure of blocking events and its response to climate change in summer and winter in Northern Hampshire $(\mathrm{NH})$ over two ocean basins (North Atlantic and North Pacific) and one land sector (Russia). Using the composite analysis of the $3 \mathrm{D}$ velocity $(u, v, \omega)$, geopotential height at $500 \mathrm{hPa}$ (Z500), $T$, and $S P$ fields in data from ERA-Interim reanalysis, two sets of large-ensemble comprehensive GCM simulations, and idealized dry and moist GCMs, we aim to address the following specific questions:

1. How does the climatological 3D structure of $\mathrm{NH}$ blocking events look like in reanalysis? Are there differences between the structures of blocking events in summer versus winter, and over land versus ocean?

2. What is the physics of the temperature anomaly under the blocking anticyclone? What are the relative roles of adiabatic processes (horizontal and vertical thermal advection) and latent heating?

3. Do comprehensive GCMs faithfully reproduce the climatological 3D structure of NH blocking events?
4. How will the 3D structure of blocking events change in the future under the RCP8.5 radiative forcing scenario?

The remainder of this paper is structured as follows. In Section 2, models, data, and methods are presented. The climatological 3D structure of blocking events and the physics of the temperature anomaly in reanalysis (Questions 1 ans 2) and 3D structure of blocking events in GCMs (Question 3) is discussed in Section 3. Response of the blocking events' 3D structure to climate change (Question 4) is analyzed in Section 4. The paper ends with a summary of the findings and discussions in Section 5.

\section{Models, Data, and Methods \\ a. Reanalysis data}

We use the 6-hourly geopotential height ( $Z), T, u, v, \omega$, and $S P$ on various levels from 1979-2019 from the ERAInterim reanalysis dataset (Dee et al. 2011). This dataset has a resolution of $0.75^{\circ} \times 0.75^{\circ}$. For each variable, daily anomalies are calculated by removing a 31-day centeredmoving average (Chan et al. 2019; Nabizadeh et al. 2019).

\section{b. Large-ensemble comprehensive GCM simulations}

We use daily data from NCAR's CESM1 LargeEnsemble Project (LENS; Kay et al. 2015) and the GFDLCM3 large-ensemble project (GFDL-LE; Donner et al. 2011; Sun et al. 2018). These two datasets consist of data from fully coupled GCM simulations at the horizontal resolution of $\sim 1^{\circ}$ (LENS) and $\sim 2.5^{\circ}$ (GFDL-LE). The LENS (GFDL-LE) ensemble has 40 (20) members for the "current climate", 1920-2005, based on the historical radiative forcing, and the same number of members for the "future climate", 2006-2100, based on the RCP8.5 radiative forcing scenario. The large number of ensemble members and the availability of daily variables in these two datasets is helpful in obtaining a high signal-to-noise ratio for climate-change response of blocking events, which are infrequent (Schaller et al. 2018; Brunner et al. 2018; Nabizadeh et al. 2019).

We use the last 25 years of each period to investigate the effects of climate change on the 3D structure of blocking events. From each dataset, we use the same variables as in Section 2a on three levels $(850,500$, and $200 \mathrm{hPa})$, except for $\omega$ that was not provided in either dataset and $S P$ that was not provided in GFDL-LE. From LENS, we also use the $2 \mathrm{~m}$ air temperature $\left(T_{2 m}\right)$. For each variable in each time period, daily anomalies are calculated by removing a 31-day centered-moving ensemble average (Nabizadeh et al. 2019). 


\section{c. Idealized dry and moist GCMs}

Two idealized GCMs are used to investigate the role of latent heating on the structure of blocking events. One is the GFDL spectral dry dynamical core GCM with the physics configuration of Held and Suarez (1994). The setup is identical to that of Hassanzadeh and Kuang (2016, 2019), in which the model has flat lower boundaries and is forced by Newtonian relaxation of temperature to a prescribed equinoctial radiative-equilibrium state. The second model is an idealized moist GCM (MiMA), which has a uniform slab ocean with a mixed layer depth of $7.5 \mathrm{~m}$, seasonal cycle, and a full radiative transfer scheme (Jucker and Gerber 2017; Garfinkel et al. 2020). Both models are run with a T63 spectral resolution with 40 vertical levels for 100,000 days, with the first 500 days in the dry GCM and first 5 years in MiMA discarded as spin up. Anomalies in the dry GCM are computed by removing the long-term mean while in MiMA, the anomalies are computed by removing a 31-day centered-moving average (Nabizadeh et al. 2019).

\section{d. Blocking index}

In ERA-Interim and all GCMs (except for the dry GCM, which is at equinox), we identify and analyze the blocking events separately in summers (June-August, JJA) and winters (December-February, DJF). Furthermore, in ERAInterim and comprehensive GCMs, we identify and analyze the blocking events separately over three sectors of the $\mathrm{NH}$ : North Atlantic $\left(60^{\circ} \mathrm{W}-30^{\circ} \mathrm{E}\right)$, North Pacific $\left(125^{\circ} \mathrm{E}-130^{\circ}\right.$ $\mathrm{W})$, and Russia $\left(31.25^{\circ} \mathrm{E}-123.75^{\circ} \mathrm{E}\right)$. We focus on the midlatitude blocking events between $40^{\circ}-60^{\circ} \mathrm{N}$.

To identify the blocking events, we employ the index of Dole and Gordon (1983), which is based on finding strong, stationary, and persistent positive daily Z500 anomalies. In a recent study by Chan et al. (2019), this index was found to perform better in identifying the heat wave-causing weather patterns compared to a few other Z500-based indices. In this index, the Z500 anomalies are first scaled by the sine of latitude following Dole and Gordon (1983) and then their standard deviation at each grid point is computed. The maximum standard deviation over latitudes $40^{\circ}-60^{\circ} \mathrm{N}$ is used to normalize the Z500 anomalies. It should be highlighted that the standard deviations used for normalizing the anomalies are calculated separately for each sector, season, time period, and GCM/dataset. In this index, grid points with normalized anomalies larger than 1.5 for at least 5 consecutive days are identified as blocked grid points (for more details, see Nabizadeh et al. 2019).

\section{e. Composite analysis}

For each blocking event, we use the average of the first 5 days of their lifetime as their representative. Following Nabizadeh et al. (2019), we identify the center of each block by finding the centroid of the 5-day averaged anomalous Z500 closed contour line of the one standard deviation around the blocked grid point. Then all these centers are shifted to one position (in latitude-longitude) and the anomalies of each variable of interest ( $v, T$ etc.) are composited.

\section{The 3D structure of blocking events: Climatology}

In this section, given our focus on 3 sectors, 2 seasons, and several variables, we will often only show the results of 1-2 representative sector(s) in the paper and highlight and discuss the similarities or differences among all seasons/sectors. Results for the rest of the sectors are presented in the Supplemental Material.

\section{a. ERA-Interim reanalysis}

Figure 1 shows the climatology of $Z$ and $v$ for the wintertime and summertime North Pacific blocking events. Figures S1 and S2 show similar plots but for blocks in the North Atlantic and Russian sectors, respectively. Consistent among the three sectors and two seasons, blocking events have an equivalent-barotropic anticyclonic pattern throughout the troposphere and lower stratosphere with strong positive $Z 500$ anomalies and a dipolar structure in the $v$ anomalies during winter and summer. One noticeable difference is that wintertime blocks are larger and stronger than the summertime blocks, consistent with previous findings (Brunner and Steiner 2017; Lupo et al. 2019; Nabizadeh et al. 2019; Hwang et al. 2020).

Next, we will first describe some of the main features of the 3D structure of the $T, \omega$, and $S P$ anomalies during blocking events, and will then analyze the adiabatic and diabatic processes in the temperature tendency equation to explain some of these features and the relative importance of these processes.

Figures 2 and 3 show the climatological $T, \omega$, and $S P$ for the North Pacific blocks in winters and summers, respectively. Figures S3-S6 show similar plots but over the North Atlantic and Russian sectors. Again, consistent among sectors and seasons, temperature has a warm anomaly throughout the troposphere under the anticyclone and then a cold anomaly in the lower stratosphere, consistent with previous findings of Green (1977) and Brunner and Steiner (2017). In winters, there is a cold temperature anomaly to the east and/or southeast side of the blocking center at 500 and $850 \mathrm{hPa}$. Furthermore, in the winters of North Pacific and North Atlantic (panels (d) and (h) of Figs. 2 and S3), there is a noticeable westward shift of the temperature anomaly in the troposphere with respect to the blocking center, which was also reported by Brunner and Steiner (2017). We will come back to explaining the underlying mechanism of this shift shortly.

The vertical velocity field $(\omega)$ has a maximum around $500 \mathrm{hPa}$ (panel (e) in Figs. 2, 3, S3-S6), and while always 
consists of a descending branch (subsidence) around or to the east of the blocking center, in some cases, such as North Pacific (both seasons), North Atlantic (winter), and Russia (summer) also consists of an equally strong ascending branch to the west in mid troposphere. Mak (1991) reported a similar dipolar structure in $\omega$ of a 3week long wintertime North Atlantic blocking event. The ascending flow on the western flank of blocking events was also shown in the results of Steinfeld et al. (2020) where they used backward air-parcel trajectories to connect the ascent on the western flank to the region of intense latent heat release. Mak (1991) also highlighted a broad region of ascending flow on the southeast side of the blocking event, which is consistent with the results of our composite analysis in the winter of both ocean basins (panel (e) of Figs. 2 and S3).

The $S P$ field also has some degree of seasonal and regional dependence. The maximum of $S P$ occurs around $850 \mathrm{hPa}$ (panel $(\mathrm{j})$ ). In all cases except for summertime Russia, see Fig. S6(j), there is a dipolar structure of positive (negative) anomaly to the west (east) of blocking center, consistent with the northward (southward) transport of moist (dry) air for the low (high) latitudes by the anticyclonic circulation.

To further explore the physics of the temperature anomalies (including the westward shift) and also the potential role of moisture, we start with the temperature tendency equation (Yanai et al. 1973; Yanai and Tomita 1998):

$$
c_{p} \frac{\partial T}{\partial t}=c_{p}\left(-\mathbf{u}_{h} \cdot \nabla T+\omega \sigma\right)+Q_{1},
$$

where $c_{p}$ is heat capacity and $\mathbf{u}_{h}=(u, v)$. Static stability $\sigma$ is defined as $\sigma=-\frac{T}{\theta} \frac{\partial \theta}{\partial p}$ where $p$ is pressure and $\theta$ is potential temperature. The first term on the right-hand side of Eq. (1) represents horizontal and vertical thermal advection, and the second term, $Q_{1}$, represents heating due to radiation and latent heating due to net condensation. To better understand the role of moisture, the latter component of $Q_{1}$ (which itself is unavailable) can be quantified by calculating the apparent moisture sink $Q_{2}$ :

$$
Q_{2}=-L \frac{\partial S P}{\partial t}-L\left(\mathbf{u}_{h} \cdot \nabla S P+\omega \frac{\partial S P}{\partial p}\right),
$$

where $L$ is the specific latent heating (Yanai et al. 1973; Yanai and Tomita 1998). $Q_{2}$ represents latent heating due to net condensation (Yanai et al. 1973). Composites of horizontal and vertical components of thermal advection and of $Q_{2} / c_{p}$ for winter and summer blocks over the North Pacific and Russia at 500 and $850 \mathrm{hPa}$ are shown in Fig. 4 (winter) and Fig. 5 (summer). Results for the North Atlantic sector are shown in Fig. S7. Note that in Figs. 4 and 5, S7, we first calculate each term using the 6-hourly full field variables and then remove each term's climatology using a 31-day centered-moving average to calculate the corresponding anomaly field (Ueda et al. 2003; Hsu and Li 2011; Li et al. 2017). Finally, the anomaly fields are centered and composited as described in Section 2.

Consistent among both seasons and three sectors, there is substantial adiabatic warming around the blocking centers, with a major contribution from vertical advection (i.e., the $\sigma \omega$ term); see the first three columns of Figs. 4, 5, S7. This warming by descending flow in some cases (e.g., both seasons of the North Pacific and North Atlantic sectors) is slightly shifted to the east, due to the dipolar pattern of $\omega$ mentioned earlier. The contribution of horizontal advection has some seasonal and regional dependence: it is either small or it consists of warming on the western and cooling on the eastern side of the blocking event (dominated by meridional advection). Using the maximum amplitude of the warming anomaly as a measure of strength, for all three regions, the total adiabatic warming is overall stronger around $850 \mathrm{hPa}$ (compared to $500 \mathrm{hPa}$ ) in winters, particularly over ocean basins, but slightly stronger around $500 \mathrm{hPa}$ over summers, particularly over Russia (see the captions of Figs. 4, 5, S7 for the values).

The $Q_{2}$ pattern also shows some seasonal and regional dependence: it is either dipolar with cooling on the eastern and warming on the western sides of the blocks, or it is monopolar with cooling around the blocking center. $Q_{2}$ is overall dominated by vertical advection of $S P$, i.e., the $\omega \partial S P / \partial p$ term in Eq. (2). Using the maximum amplitude of the cooling anomaly as a measure of strength, $Q_{2}$ is always stronger around $850 \mathrm{hPa}$ (compared to $500 \mathrm{hPa}$ ) and at this level, is overall as strong as total adiabatic warming in summers but weaker than total adiabatic warming in winters, particularly over the ocean basins (see the captions of Figs. 4, 5, S7 for the values). Below we further discuss some of the seasonal and regional dependences of the adiabatic warming and latent heating.

In winters of North Pacific and North Atlantic, in addition to the warming around the center mentioned above, there is cooling (warming) on the southern/eastern (western) side of the blocks; see Figs. 2(d),(h) and S3(d),(h). The cooling on the southern/eastern side is due to a combination of horizontal thermal advection (dominated by meridional advection from higher latitudes), vertical advection, and the east-west dipolar structure of $Q_{2}$ (Figs. 4(a)-(h) and S7(a)-(h)). The warming on the western side of these blocks is due to latent heating, i.e., the anomalously positive $Q_{2}$ on the western side (Figs. 4(d),(h) and S7(d),(h)). The results are consistent with those of Steinfeld and Pfahl (2019), where the contribution of latent heating (upstream) is found to be large for blocks over the oceans during $\mathrm{NH}$ winters. Our analysis suggests that the westward shift of $T$, particularly in the winter of North Pacific, that was noted earlier, is due to latent heating. This is further confirmed using idealized modeling experiments. Figure S8 shows the longitude-pressure (as well as latitudepressure) composites of $T$ for blocking events simulated in 
the idealized dry GCM (panel (a)) and summer (panel (b)) and winter (panel (c)) of the idealized moist GCM. The structure of $T$ anomaly is aligned with the blocking center in the dry case while there is a westward shift in the moist case, most notably in winters when latent heating has a stronger effect.

In winters over Russia, horizontal thermal advection has a small contribution compared to vertical advection except in the south-east side of the blocks, where it leads to cooling particularly around $850 \mathrm{hPa}$ (Fig. 4(m),(o)), consistent with the cold anomaly in Fig. S5(h). Furthermore, $Q_{2}$ is negative and has a monopolar structure around the center (Fig 4(i)-(p)), weakening the adiabatic warming due to vertical advection. As a result, the structure of $T$ is a positive anomaly around the center and a negative anomaly on the south-east side of blocks. Due to monopolar structure of $Q_{2}$, the $T$ anomaly does not have the westward shift.

During summer, in addition to the adiabatic warming around the blocking centers due to vertical advection in all the three sectors, there is weak cooling on the eastern side due to meridional advection and a negative $Q_{2}$ pattern around the center and to the east. Contribution of upstream latent heating is larger over Russia during summer compared to winter, where latent heating is insignificant (Fig. 5(1),(p)). This is in agreement with the results of Steinfeld and Pfahl (2019) and Zschenderlein et al. (2019), who found that in summers, there are some contributions from latent heating in the up-stream regions of continental blocks.

In short, aside from the dominant role of adiabatic warming by vertical advection in all sectors and both seasons, contributions of horizontal adiabatic warming and latent heating vary by region and season. Understanding the reasons behind these dependencies require further analysis of the regional and seasonal background flows and temperature fields as well as the physics giving rise to dipolar versus monopolar blocks' $\omega$ structure (which is associated with the $Q_{2}$ and adiabatic warming patterns). While such analysis is beyond the scope of this paper, we hope that our findings motivate future work.

Finally, thermal wind balance explains the cold anomaly in lower stratosphere that is seen in all cases (also clearly seen in the idealized dry and moist GCMs, Fig. S8). For example, on the poleward (eastern) side of the block, anomalous $u(v)$ is eastward (southward) and increases in magnitude from the surface to near the tropopause, above which the magnitude declines. As a result, $\partial u / \partial p<0$ $(\partial v / \partial p>0)$ in the troposphere, leading to $\partial T / \partial y(\partial T / \partial x)$ that is negative, thus a positive $T$ anomaly under the anticyclone. In the lower stratosphere, $\partial u / \partial p>0(\partial v / \partial p<0)$, leading to positive $\partial T / \partial y(\partial T / \partial x)$, thus a negative $T$ anomaly above the anticyclone. For the same reason, similar cold anomaly in lower stratosphere above a warm anomaly in the troposphere is seen in the pattern of the temperature anomaly associated with the leading EOF of zonal-mean zonal wind (i.e., the annular mode) in both hemispheres (Thompson and Li 2015; Ma et al. 2017; Hassanzadeh and Kuang 2019).

\section{b. Large-ensemble fully coupled GCM simulations}

Before using the simulations in the LENS and GFDLLE datasets to understand how the 3D structure of blocking events might respond to climate change, here we aim to examine how well these models reproduce the climatology of the blocking events' 3D structure. Figures 6 and 7 show the 1981-2005 climatology of 3D structure of wintertime and summertime North Pacific blocking events in LENS using the same variables used from reanalysis (with the exception of $\omega, Z 200$, and $Z 850$, which were not available). Figures S9-S12 show similar results but for the North Atlantic and Russian sectors. Comparing these results with those from reanalysis (Figs. 1-3, S1-S6) shows that the NCAR's CESM1 model reproduces the patterns and amplitudes associated with the 3D structure of blocking events faithfully over all three sectors and in both summers and winters. In particular, the sometimes complex patterns of $T$ and $S P$ and the regional and seasonal dependencies discussed earlier (e.g., the westward shift of $T$ ) are well reproduced by the model. One exception might appear to be the pattern of $T$ in summers at 500 and $850 \mathrm{hPa}$ over all regions, which includes broad cooling regions around the central warming region of the blocks in the model but not in reanalysis. However, a closer examination of the reanalysis data shows that similar broad cooling exists but not at the $95 \%$ level used for statistical significance here.

Analysis of the GFDL-LE dataset (no shown) demonstrates that the GFDL-CM3 model reproduces the climatology of the blocking events' 3D structure similarly well (note that the daily $S P$ and $\omega$ fields were not available for examination).

The above findings, i.e., that CEMS1 and GFDL-CM3 fully coupled models reproduce the climatology of the 3D structure of blocking event very well, are interesting given that these models are known to have biases in reproducing the climatological NH large-scale circulation (Kwon et al. 2018; Athanasiadis et al. 2020) and are known to underestimate blocking frequency (Lee and Ahn 2017; Kwon et al. 2018; Athanasiadis et al. 2020), which is a persistent bias in generations of comprehensive climate models (Barnes et al. 2012; Davini and Cagnazzo 2014; Lee and Ahn 2017; Matsueda and Endo 2017; Jiang et al. 2019; Simpson et al. 2020). This issue will be further discussed in the next section.

\section{Response of the blocking events' 3D structure to cli- mate change}

In this section, we study the response of the 3D structure of blocking events to climate change using the two large-ensemble datasets. To compute the response of each 
variable, we first calculate the composited anomaly in the current and future climates, separately, and then calculate the difference (as future minus current). This approach has been used recently in some studies of Euro-Atlantic blocking events (Masato et al. 2014; Kennedy et al. 2016). We start with the response in summers and then discuss the response in winters.

\section{a. Summer (JJA)}

The responses of the blocking events' Z500 field over the three sectors in summers are shown in Fig. 8 (the two left columns). Both models predict a weakening of $Z 500$ around the blocking center over all three regions, although the decline is much stronger in the GFDL-CM3 model (and in LENS over North Atlantic, there is small strengthening of $Z 500$ on the sides). Examining the tropospheric $u$ response (Fig. S13) demonstrates a robust weakening at both 850 and $500 \mathrm{hPa}$ in both models and all regions, consistent with the overall decrease in Z500. Figures 9 and 10 show responses of temperature anomalies in the LENS and GFDL-LE datasets, respectively. At $200 \mathrm{hPa}$, consistent among models and regions, there is a positive response, i.e., weakening of the blocking events' cold temperature anomaly in lower stratosphere. Both models also predict cooling in the troposphere, i.e., weakening of the blocks' temperature anomaly, with 3 exceptions: the response of $T$ at $850 \mathrm{hPa}$ over the North Atlantic and Russia in LENS is positive while over North Atlantic in GFDL-LE is near zero around the blocking center (panels (h)-(i)).

In order to understand what causes this discrepancy between the model predictions, we analyze the results of self-organizing map (SOM; Kohonen 2012) clustering of blocking events over the North Atlantic and Russian sectors in the reanalysis and in the two models. Here, we have clustered Z500 anomalies associated with blocking events in the current climate into two distinguishable clusters using a map of 2 by 1 nodes (the SOM algorithm and details are the same as those described in Hassanzadeh et al. (2020)). As shown in Fig. S15, the GFDL-CM3 model accurately captures the frequencies and locations/patterns of clusters over Scandinavia and the Atlantic ocean. However, the CESM1 model does not capture the frequencies of these two separate classes, and the locations/patterns are not entirely the same as those in the reanalysis. Further analysis (not shown) shows that cluster 1 in the LENS dataset, which is overestimated, has a strongly positive $T$ response at the low levels, resembling the total positive response Fig. 9(h). A similar clustering analysis has been performed over Russia. Although both models are relatively able to capture the frequencies and patterns of blocking events in the current over this sector, their future locations/patterns are entirely different (Fig. S16), which leads to different responses in $T$ (and other fields). Overall, the temperature anomalies associated with summertime blocking events are projected to weaken under climate change, except over Russia where there is disagreement among the two models.

It should be noted that these apparent weakening of the $Z 500$ and $T$ anomalies do not necessarily mean weakening of the impact of blocking events in the future. While the response of blocking events over North Atlantic (and perhaps Russia) seems less trustworthy in LENS, this dataset provides daily near-surface air temperature, $T 2 m$. With this caveat in mind, Fig. 11 shows the response of $T 2 \mathrm{~m}$ associated with blocking events. Over Russia (panel (e)), where the $T 2 m$ anomaly is already the largest (and positive), the predicted response is positive near the blocking center, further amplifying the impact of future heat waves over this region. The response over the ocean basins is more complex, but there are both cooling and warming under the block. Note that the sign of the response in the near-surface temperature depends on factors beyond just the change in the strength of the blocking events; examples of other factors are changes in the large-scale background zonal and meridional temperature gradients (Schneider et al. 2015; Holmes et al. 2016) and over land, changes in the soil-moisture feedback Fischer et al. (2007); Hauser et al. (2016); Rasmijn et al. (2018). To gain a deeper understanding, further analyses in the future studies, particularly using large-ensemble model outputs that include daily (or sub-daily) $\omega$ and $S P$, are needed.

In contrast to other variables discussed so far, the $S P$ anomaly associated with the blocking events is projected to strengthen in future summers (Fig. 12; only for LENS, in which daily $S P$ was available). Over the two ocean basins, and particularly at $850 \mathrm{hPa}$ over North Pacific, the response of $S P$ is generally positive (negative) on the western (eastern) side, reinforcing the $S P$ anomaly associated with the blocking events. Over Russia, the response is mainly negative on the eastern side and around the center and to a lesser degree positive on the western side, but again strengthening the $S P$ anomaly.

To summarize, the response of summertime blocking events to climate change is overall, weakening of $Z 500$, wind, and $T$ anomalies and strengthening of $S P$ anomalies, although the responses are much stronger in GFDL-LE, and the two models disagree over the sign of the low-level $T$ response over Russia.

\section{b. Winter (DJF)}

The responses of the blocking events' Z500 field over the three sectors in winters are shown in Fig. 8 (the two right columns). Both models agree on the strengthening of $Z 500$ over North Pacific (first row). Over North Atlantic and Russia, GFDL-CM3 predicts strengthening of $Z 500$ while CESM1 predicts small responses (though positive and statistically significant). Overall, the responses in Z500 are positive, but unlike summer, spatially non-uniform, and often shifted westward (more discussion to follow). These 
results are consistent with those of Kennedy et al. (2016) who found that the Z500 anomalies of European blocks non-uniformly strengthen in the future. Consistent with the $Z 500$ responses, examining the tropospheric $u$ response (Fig. S14) shows clear strengthening in all 3 sectors in GFDL-LE and in North Pacific in LENS, but a more complicated response in the other two sectors.

Figures 13 and 14 show responses of temperature anomalies in the LENS and GFDL-LE datasets, respectively. Like summertime responses, both models predict warming at $200 \mathrm{hPa}$, which weakens the cold $T$ anomaly associated with blocking events in lower stratosphere (panels (a)-(c)). Over North Pacific, both models agree on substantial cooling at $850 \mathrm{hPa}$ and some cooling at $500 \mathrm{hPa}$, although there is also weak warming on the western sides on both levels (panels (d) and (g)). Over Russia, both models predict westward-shifted warming at $500 \mathrm{hPa}$ and cooling near the center and warming on the western side at $850 \mathrm{hPa}$ (panels (f) and (i)). Finally, over North Atlantic, while both models show warming around the center and western side at $500 \mathrm{hPa}$, they do not agree on the sign of the response at $850 \mathrm{hPa}($ panel (h)).

The response of $S P$ anomaly associated with blocking events shows straightening over all three sectors, especially over North Pacific and North Atlantic (Fig. 12). Over these two ocean sectors, there is positive (negative) $S P$ response on the western (eastern) side of the blocking center. These results suggest that increased latent heating, due to increased low-level moisture, is likely responsible for the positive $T$ response on the western side, which itself drives the noticeable westward-shifted strengthening of Z500 mentioned earlier (Fig. 8). Confirming this connection requires future work using large-ensemble model outputs (including $\omega$ and $S P$ ) with sub-daily sampling such that the temperature tendency equation could be thoroughly analyzed (as done in Section 3).

Finally, the weakening of the low-level $T$ anomalies in winter is also manifested in the weakening of $T 2 \mathrm{~m}$ associated with blocks over North Pacific, Russia, and even North Atlantic (Fig. 11). The latter is consistent with the results of Kennedy et al. (2016) and Masato et al. (2014).

\section{Discussions and summary}

In this paper, we present a composite analysis of current and future NH blocking events' 3D structure by analyzing $Z 500,3 \mathrm{D}$ velocity field, temperature, and specific humidity, and in some cases their connections, at three levels: 200,500 , and $850 \mathrm{hPa}$. We aim to answer four specific questions, which are listed in the Introduction.

With regard to Question 1, which is about the climatology of blocking events, the reanalysis data show that over both ocean and land and in both seasons, the anomalous anticyclonic winds are equivalent-barotropic in the troposphere and stratosphere, and the temperature anomalies are positive throughout the troposphere and negative in the lower stratosphere. The main seasonal and regional differences are that blocks are larger and stronger in winters, and over oceans, the temperature anomaly is shifted westward, most noticeably in winters. Further analysis shows that this westward shift, which is reproduced even in an idealized moist GCM, is due to latent heating on the up-stream region of blocking events. Overall, there is subsidence near the blocking center, although in some cases (e.g., over North Pacific), this descending branch is shifted eastward and accompanied by an equally strong ascending branch to the west, creating a dipolar structure for $\omega$. In general, the findings about the climatology (including the westward shift and role of latent heating) are consistent with those reported in various earlier papers focused on case studies or blocking events of specific regions or seasons (e.g., Mak 1991; Brunner and Steiner 2017; Steinfeld and Pfahl 2019).

To address Question 2, which is about the physics driving the positive temperature anomaly under the anticyclone, we quantify the contributions of horizontal and vertical thermal advection and latent heating due to net condensation $Q_{2}$ in the temperature tendency equation using reanalysis data. Consistent among both seasons and three sectors, we find adiabatic warming due to subsidence as a major contributor to warming near the center of blocking events, although the warming could be slightly shifted eastward when $\omega$ has a dipolar structure. Depending on the season, region, and level, meridional advection and $Q_{2}$ can also have leading-order contributions to the thermal budget under the anticyclone. For example, for wintertime North Pacific blocks, at $850 \mathrm{hPa}$, the total adiabatic warming (due to both vertical and meridional advection) is much stronger than $Q_{2}$, but the up-stream latent heating still leads to the noticeable westward shift of $T$ anomaly. As another example, in summertime Russian blocks, the $850 \mathrm{hPa}$ total adiabatic warming (dominated by vertical advection) and anomalously negative $Q_{2}$ around the center and latent heating on the west have comparable magnitudes. Overall, these findings, particularly on the dominant role of adiabatic warming due to subsidence and the importance of latent heating, are consistent with those recently reported for European blocks/heat waves and/or using Lagrangian trajectory analysis (e.g., Steinfeld and Pfahl 2019; Zschenderlein et al. 2019).

With regard to Question 3, we find that both CESM1 and GFDL-CM3 can reproduce the climatological 3D structure of blocking events, including the patterns of temperature and specific humidity anomalies, over all three sectors and in both seasons remarkably well. That said, we also find through clustering analysis that CESM1 (unlike GFDLCM3) does not reproduce the relative frequency and location of blocks over Atlantic Ocean vs. Scandinavia well, leading to disagreement with GFDL-CM3 on the future response over the North Atlantic sector. 
To address Question 4, about the response of the 3D structure to climate change, we examine the difference in the composites of the anomalies at the end of $21^{\text {st }}$ century versus the end of $20^{\text {th }}$ century under RCP8.5. We find both models to overall agree on the sign of the response, although there are a few disagreements, and responses are generally stronger in GFDL-LE compared to LENS. In summers, we find a general weakening of all anomalous fields, except for specific humidity anomaly, which becomes stronger. However, in LENS, which provides daily $2 \mathrm{~m}$ air temperature, we find that this weakening does not necessarily translate to a weakening of the impact on near-surface temperature extremes. Most notably, the warm temperature anomaly associated with Russian blocking events is projected to intensify. Note that this increase in near-surface positive temperature anomaly, in spite of the apparent weakening of the block, is not because of the increase in the mean surface temperature due to climate change (since anomalies in each time period are computed with respect to the climatology of that period). Rather, this increase is likely due to changes in the large-scale background temperature gradients and potentially land feedbacks. Given the implications of this increase in near-surface warming for future heat waves in Russia, future studies should further examine the robustness of this projection in more models and investigate the underlying mechanism.

In winters, there is a general spatially non-uniform strengthening of all fields, with the exception of temperature anomalies. The stratospheric temperature anomalies in all cases and tropospheric temperature anomalies in some cases, particularly at $850 \mathrm{hPa}$, are projected to weaken, leading to responses of opposite signs at $850 \mathrm{hPa}$ and $500 \mathrm{hPa}$ in some sectors, for example, over Russia. Furthermore, the response of Z500 is noticeably westward shifted, which is due to the anomalously positive temperature response on the western side of the blocks (even when there is cooling around the center at that level, e.g., over North Pacific). Based on the analysis of the temperature tendency equation performed for reanalysis data, this positive temperature anomaly is attributed to increased upstream latent heating, but this could not be confirmed due to the unavailability of sub-daily (or even daily) $\omega$. Based on the LENS dataset alone, in winters, unlike summers, there is substantial weakening of the near-surface warm anomaly under the anticyclone, particularly over North Pacific and Russia.

To summarize, our analysis suggests that latent heating plays an important role in setting the blocking events' 3D structure and its response to climate change, in both seasons and over both land and ocean. These findings add to the growing body of evidence on the importance of latent heating for blocking dynamics that has emerged from a number of recent studies, particularly from pioneering work by Pfahl and collaborators (e.g., Pfahl et al. 2015;
Steinfeld and Pfahl 2019; Steinfeld et al. 2020). Our analysis also shows that to understand the effects of climate change on blocking events and their impact on surface temperature extremes, in particular in summers, further work focused on each region, and even with each region separated into at least two clusters, is needed. A thorough analysis requires multi-model, large-ensemble simulation outputs that include sub-daily (or at least daily) horizontal and vertical velocity, temperature, and specific humidity, some of which were not available at this point through LENS and GFDL-LE datasets. Such analyses might shed light on the relation between the strength of the blocks and their impact on surface temperature extremes, and the reasons behind the increased near-surface warming in summers and height-dependent response of tropospheric temperature in winters. Additional analysis of changes in synoptic eddy forcings and energetic of blocking events will be needed to investigate the reason(s) for the general strengthening and weakening of most anomalous fields in winters and summers, respectively, and the larger amplitudes of GFDL-CM3 responses. That said, the lack of a complete mechanistic understanding of blocking events, and the potential of different mechanisms dominating blocking dynamics in different regions (Drouard and Woollings 2018; Woollings et al. 2018), can complicate answering those questions unambiguously at this point.

Acknowledgments. This work is supported by NSF grant AGS-1921413 and NASA grant 80NSSC17K0266. Computational resources were provided by XSEDE (allocation ATM170020), NCAR's CISL (allocation URIC0004), and Rice University Center for Research Computing.

Data availability statement. The ERA-Interim reanalysis is publicly available from the European Centre for Medium-Range Weather Forecasts (ECMWF) at https://www.ecmwf.int/en/forecasts/ datasets/reanalysis-datasets/era-interim.

Both large-ensemble datasets, the National Center for Atmospheric Research (NCAR) Community Earth System Model (CESM) Large Ensemble Community Project (LENS) and the Geophysical Fluid Dynamics Laboratory (GFDL) Climate Model version 3 (CM3) Large Ensemble Project (GFDL-LE), are publicly available at http://www.cesm.ucar.edu/ projects/community-projects/LENS/ (LENS) and https://www. earthsystemgrid.org/dataset/ ucar.cgd.ccsm4.CLIVAR_LE.gfdl_cm3_lens.html (GFDL-LE). Both idealized GCMs are available online at https://mjucker.github.io/MiMA (moist model) and https://wWw.gfdl.noaa.gov/ idealized-spectral-models-quickstart/ (dry model). 


\section{References}

Athanasiadis, P. J., S. Yeager, Y.-O. Kwon, A. Bellucci, D. W. Smith, and S. Tibaldi, 2020: Decadal predictability of North Atlantic blocking and the NAO. npj Climate and Atmospheric Science, 3 (1), 1-10.

Barnes, E. A., E. Dunn-Sigouin, G. Masato, and T. Woollings, 2014: Exploring recent trends in Northern Hemisphere blocking. Geophysical Research Letters, 41 (2), 638-644.

Barnes, E. A., and L. M. Polvani, 2015: CMIP5 projections of Arctic amplification, of the North American/North Atlantic circulation, and of their relationship. Journal of Climate, 28 (13), 5254-5271.

Barnes, E. A., J. Slingo, and T. Woollings, 2012: A methodology for the comparison of blocking climatologies across indices, models and climate scenarios. Climate Dynamics, 38 (11-12), 2467-2481.

Barriopedro, D., E. M. Fischer, J. Luterbacher, R. M. Trigo, and R. García-Herrera, 2011: The hot summer of 2010: redrawing the temperature record map of Europe. Science, 332 (6026), 220-224.

Bieli, M., S. Pfahl, and H. Wernli, 2015: A Lagrangian investigation of hot and cold temperature extremes in Europe. Quarterly Journal of the Royal Meteorological Society, 141 (686), 98-108.

Brunner, L., G. C. Hegerl, and A. K. Steiner, 2017: Connecting atmospheric blocking to European temperature extremes in spring. Journal of Climate, 30 (2), 585-594.

Brunner, L., N. Schaller, J. Anstey, J. Sillmann, and A. K. Steiner, 2018: Dependence of present and future European temperature extremes on the location of atmospheric blocking. Geophysical Research Letters, 45 (12), 6311-6320.

Brunner, L., and A. K. Steiner, 2017: A global perspective on atmospheric blocking using GPS radio occultation-one decade of observations. Atmospheric Measurement Techniques, 10 (12).

Cash, B. A., and S. Lee, 2000: Dynamical processes of block evolution. Journal of the Atmospheric Sciences, 57 (19), 3202-3218.

Chan, P.-W., P. Hassanzadeh, and Z. Kuang, 2019: Evaluating indices of blocking anticyclones in terms of their linear relations with surface hot extremes. Geophysical Research Letters, 46 (9), 4904-4912.

Coumou, D., G. Di Capua, S. Vavrus, L. Wang, and S. Wang, 2018: The influence of Arctic amplification on mid-latitude summer circulation. Nature Communications, 9 (1), 2959.

Davini, P., and C. Cagnazzo, 2014: On the misinterpretation of the North Atlantic Oscillation in CMIP5 models. Climate Dynamics, 43 (5-6), 1497-1511.

Davini, P., and F. D'Andrea, 2020: From CMIP-3 to CMIP-6: Northern Hemisphere atmospheric blocking simulation in present and future climate. Journal of Climate, 1-50.

Dee, D. P., and Coauthors, 2011: The ERA-Interim reanalysis: Configuration and performance of the data assimilation system. Quarterly Journal of the royal meteorological society, 137 (656), 553-597.

Dole, R., and N. Gordon, 1983: Persistent anomalies of the extratropical Northern Hemisphere wintertime circulation: Geographical distribution and regional persistence characteristics. Monthly Weather Review, 111 (8), 1567-1586.

Dole, R., and Coauthors, 2011: Was there a basis for anticipating the 2010 Russian heat wave? Geophysical Research Letters, 38 (6).
Donner, L. J., and Coauthors, 2011: The dynamical core, physical parameterizations, and basic simulation characteristics of the atmospheric component AM3 of the GFDL global coupled model CM3. Journal of Climate, 24 (13), 3484-3519.

Drouard, M., and T. Woollings, 2018: Contrasting mechanisms of summer blocking over western Eurasia. Geophysical Research Letters, 45 (21), 12-040.

Fischer, E. M., S. I. Seneviratne, P. L. Vidale, D. Lüthi, and C. Schär, 2007: Soil moisture-atmosphere interactions during the 2003 European summer heat wave. Journal of Climate, 20 (20), 5081-5099.

Garfinkel, C. I., I. White, E. P. Gerber, M. Jucker, and M. Erez, 2020: The building blocks of Northern Hemisphere wintertime stationary waves. Journal of Climate, 33 (13), 5611-5633.

Green, J., 1977: The weather during July 1976: Some dynamical considerations of the drought. Weather, 32 (4), 120-126.

Hassanzadeh, P., and Z. Kuang, 2015: Blocking variability: Arctic amplification versus Arctic Oscillation. Geophysical Research Letters, 42 (20), 8586-8595.

Hassanzadeh, P., and Z. Kuang, 2016: The linear response function of an idealized atmosphere. Part I: Construction using Green's functions and applications. Journal of the Atmospheric Sciences, 73 (9), 34233439.

Hassanzadeh, P., and Z. Kuang, 2019: Quantifying the annular mode dynamics in an idealized atmosphere. Journal of the Atmospheric Sciences, (2019).

Hassanzadeh, P., Z. Kuang, and B. F. Farrell, 2014: Responses of midlatitude blocks and wave amplitude to changes in the meridional temperature gradient in an idealized dry GCM. Geophysical Research Letters, 41 (14), 5223-5232.

Hassanzadeh, P., C.-Y. Lee, E. Nabizadeh, S. J. Camargo, D. Ma, and L. Y. Yeung, 2020: Effects of climate change on the movement of future landfalling texas tropical cyclones. Nature Communications, 11 (1), 1-9.

Hauser, M., R. Orth, and S. I. Seneviratne, 2016: Role of soil moisture versus recent climate change for the 2010 heat wave in western Russia. Geophysical Research Letters, 43 (6), 2819-2826.

Held, I., and M. Suarez, 1994: A proposal for the intercomparison of the dynamical cores of atmospheric general circulation models. Bulletin of the American Meteorological Society, 75 (10), 1825-1830.

Holmes, C. R., T. Woollings, E. Hawkins, and H. De Vries, 2016: Robust future changes in temperature variability under greenhouse gas forcing and the relationship with thermal advection. Journal of Climate, 29 (6), 2221-2236.

Horton, D. E., N. C. Johnson, D. Singh, D. L. Swain, B. Rajaratnam, and N. S. Diffenbaugh, 2015: Contribution of changes in atmospheric circulation patterns to extreme temperature trends. Nature, $\mathbf{5 2 2}$ (7557), 465 .

Hoskins, B. J., and I. N. James, 2014: Fluid dynamics of the mid-latitude atmosphere. John Wiley \& Sons.

Hsu, P.-C., and T. Li, 2011: Interactions between boreal summer intraseasonal oscillations and synoptic-scale disturbances over the western North Pacific. part II: Apparent heat and moisture sources and eddy momentum transport. Journal of climate, 24 (3), 942-961. 
Huguenin, M. F., E. M. Fischer, S. Kotlarski, S. C. Scherrer, C. Schwierz, and R. Knutti, 2020: Lack of change in the projected frequency and persistence of atmospheric circulation types over Central Europe. Geophysical Research Letters, 47 (9), e2019GL086 132.

Hwang, J., P. Martineau, S.-W. Son, T. Miyasaka, and H. Nakamura, 2020: The role of transient eddies in North Pacific blocking formation and its seasonality. Journal of the Atmospheric Sciences, 77 (7), 2453-2470.

Illari, L., and J. C. Marshall, 1983: On the interpretation of eddy fluxes during a blocking episode. Journal of the Atmospheric Sciences, 40 (9), 2232-2242.

Jiang, T., K. Evans, M. Branstetter, P. Caldwell, R. Neale, P. J. Rasch, Q. Tang, and S. Xie, 2019: Northern Hemisphere blocking in 25$\mathrm{km}$-resolution E3SM v0. 3 atmosphere-land simulations. Journal of Geophysical Research: Atmospheres, 124 (5), 2465-2482.

Jucker, M., and E. Gerber, 2017: Untangling the annual cycle of the tropical tropopause layer with an idealized moist model. Journal of Climate, 30 (18), 7339-7358.

Kay, J., and Coauthors, 2015: The Community Earth System Model (CESM) large ensemble project: A community resource for studying climate change in the presence of internal climate variability. Bulletin of the American Meteorological Society, 96 (8), 1333-1349.

Kennedy, D., T. Parker, T. Woollings, B. Harvey, and L. Shaffrey, 2016: The response of high-impact blocking weather systems to climate change. Geophysical Research Letters, 43 (13), 7250-7258.

Kohonen, T., 2012: Self-organizing maps, Vol. 30. Springer Science \& Business Media.

Kwon, Y.-O., A. Camacho, C. Martinez, and H. Seo, 2018: North Atlantic winter eddy-driven jet and atmospheric blocking variability in the Community Earth System Model version 1 Large Ensemble simulations. Climate Dynamics, 51 (9), 3275-3289.

Lee, D. Y., and J.-B. Ahn, 2017: Future change in the frequency and intensity of wintertime North Pacific blocking in CMIP5 models. International Journal of Climatology, 37 (5), 2765-2781.

Lenggenhager, S., M. Croci-Maspoli, S. Brönnimann, and O. Martius, 2019: On the dynamical coupling between atmospheric blocks and heavy precipitation events: A discussion of the southern Alpine flood in October 2000. Quarterly Journal of the Royal Meteorological Society, 145 (719), 530-545.

Li, L., R. Zhang, and M. Wen, 2017: Genesis of southwest vortices and its relation to Tibetan Plateau vortices. Quarterly Journal of the Royal Meteorological Society, 143 (707), 2556-2566.

Luo, D., W. Zhang, L. Zhong, and A. Dai, 2019: A nonlinear theory of atmospheric blocking: A potential vorticity gradient view. Journal of the Atmospheric Sciences, 76 (8), 2399-2427.

Lupo, A. R., A. D. Jensen, I. I. Mokhov, A. V. Timazhev, T. Eichler, and B. Efe, 2019: Changes in global blocking character in recent decades. Atmosphere, 10 (2), 92.

Lupo, A. R., and P. J. Smith, 1995: Planetary and synoptic-scale interactions during the life cycle of a mid-latitude blocking anticyclone over the North Atlantic. Tellus A, 47 (5), 575-596.

Ma, D., P. Hassanzadeh, and Z. Kuang, 2017: Quantifying the eddyjet feedback strength of the annular mode in an idealized $\mathrm{gcm}$ and reanalysis data. Journal of the Atmospheric Sciences, 74 (2), 393407.

Ma, J., and X. San Liang, 2017: Multiscale dynamical processes underlying the wintertime Atlantic blockings. Journal of the Atmospheric Sciences, 74 (11), 3815-3831.

Mak, M., 1991: Dynamics of an atmospheric blocking as deduced from its local energetics. Quarterly Journal of the Royal Meteorological Society, 117 (499), 477-493.

Masato, G., T. Woollings, and B. Hoskins, 2014: Structure and impact of atmospheric blocking over the Euro-Atlantic region in presentday and future simulations. Geophysical Research Letters, 41 (3), 1051-1058.

Matsueda, M., and H. Endo, 2017: The robustness of future changes in Northern Hemisphere blocking: A large ensemble projection with multiple sea surface temperature patterns. Geophysical Research Letters, 44 (10), 5158-5166.

Nabizadeh, E., P. Hassanzadeh, D. Yang, and E. A. Barnes, 2019: Size of the atmospheric blocking events: Scaling law and response to climate change. Geophysical Research Letters, 46 (22), 13 488-13 499.

Nakamura, H., M. Nakamura, and J. L. Anderson, 1997: The role of high-and low-frequency dynamics in blocking formation. Monthly Weather Review, 125 (9), 2074-2093.

Nakamura, N., and C. S. Huang, 2018: Atmospheric blocking as a traffic jam in the jet stream. Science, 361 (6397), 42-47.

Narinesingh, V., J. F. Booth, S. K. Clark, and Y. Ming, 2020: Atmospheric blocking: The impact of topography in an idealized general circulation model. Weather and Climate Dynamics Discussions, 139.

Patterson, M., T. Bracegirdle, and T. Woollings, 2019: Southern Hemisphere atmospheric blocking in CMIP5 and future changes in the Australia-New Zealand sector. Geophysical Research Letters, 46(15), 9281-9290.

Peings, Y., J. Cattiaux, S. Vavrus, and G. Magnusdottir, 2017: Late twenty-first-century changes in the midlatitude atmospheric circulation in the CESM large ensemble. Journal of Climate, 30 (15), 5943-5960.

Pfahl, S., C. Schwierz, M. Croci-Maspoli, C. M. Grams, and H. Wernli, 2015: Importance of latent heat release in ascending air streams for atmospheric blocking. Nature Geoscience, 8 (8), 610.

Pfahl, S., and H. Wernli, 2012: Quantifying the relevance of atmospheric blocking for co-located temperature extremes in the Northern Hemisphere on (sub-) daily time scales. Geophysical Research Letters, 39 (12).

Rasmijn, L., G. Van der Schrier, R. Bintanja, J. Barkmeijer, A. Sterl, and W. Hazeleger, 2018: Future equivalent of 2010 Russian heatwave intensified by weakening soil moisture constraints. Nature Climate Change, 8 (5), 381-385.

Rex, D., 1950: Blocking action in the middle troposphere and its effect upon regional climate: I. an aerological study of blocking action. Tellus, 2 (3), 196-211.

Röthlisberger, M., and O. Martius, 2019: Quantifying the local effect of Northern Hemisphere atmospheric blocks on the persistence of summer hot and dry spells. Geophysical Research Letters, 46 (16), $10101-10111$. 
Schaller, N., J. Sillmann, J. Anstey, E. M. Fischer, C. M. Grams, and S. Russo, 2018: Influence of blocking on Northern European and Western Russian heatwaves in large climate model ensembles. Environmental Research Letters, 13 (5), 054015.

Schneider, T., T. Bischoff, and H. Płotka, 2015: Physics of changes in synoptic midlatitude temperature variability. Journal of Climate, 28 (6), 2312-2331.

Shutts, G., 1983: The propagation of eddies in diffluent jetstreams: Eddy vorticity forcing of 'blocking' flow fields. Quarterly Journal of the Royal Meteorological Society, 109 (462), 737-761.

Simpson, I. R., and Coauthors, 2020: An evaluation of the large-scale atmospheric circulation and its variability in CESM2 and other CMIP models. Journal of Geophysical Research: Atmospheres, 125 (13), e2020JD032 835 .

Steinfeld, D., M. Boettcher, R. Forbes, and S. Pfahl, 2020: The sensitivity of atmospheric blocking to changes in upstream latent heatingnumerical experiments. Weather and Climate Dynamics, 1 (2), 405426.

Steinfeld, D., and S. Pfahl, 2019: The role of latent heating in atmospheric blocking dynamics: a global climatology. Climate Dynamics, 53 (9-10), 6159-6180.

Sun, L., M. Alexander, and C. Deser, 2018: Evolution of the global coupled climate response to Arctic sea ice loss during 1990-2090 and its contribution to climate change. Journal of Climate, 31 (19), 7823-7843.

Thompson, D. W., and Y. Li, 2015: Baroclinic and barotropic annular variability in the Northern Hemisphere. Journal of the Atmospheric Sciences, 72 (3), 1117-1136.

Tsou, C.-H., and P. J. Smith, 1990: The role of synoptic/planetary-scale interactions during the development of a blocking anticyclone. Tellus A: Dynamic Meteorology and Oceanography, 42 (1), 174-193.

Ueda, H., H. Kamahori, and N. Yamazaki, 2003: Seasonal contrasting features of heat and moisture budgets between the eastern and western Tibetan Plateau during the GAME IOP. Journal of climate, 16 (14), 2309-2324.

Wehrli, K., B. P. Guillod, M. Hauser, M. Leclair, and S. I. Seneviratne, 2019: Identifying key driving processes of major recent heat waves. Journal of Geophysical Research: Atmospheres, 124 (22), 11 74611765.

Wiedenmann, J. M., A. R. Lupo, I. I. Mokhov, and E. A. Tikhonova, 2002: The climatology of blocking anticyclones for the Northern and Southern Hemispheres: Block intensity as a diagnostic. Journal of Climate, 15 (23), 3459-3473.

Woollings, T., and Coauthors, 2018: Blocking and its response to climate change. Current Climate Change Reports, 4 (3), 287-300.

Yamazaki, A., and H. Itoh, 2013: Vortex-vortex interactions for the maintenance of blocking. part I: The selective absorption mechanism and a case study. Journal of the Atmospheric Sciences, 70 (3), 725742 .

Yanai, M., S. Esbensen, and J.-H. Chu, 1973: Determination of bulk properties of tropical cloud clusters from large-scale heat and moisture budgets. Journal of the Atmospheric Sciences, 30 (4), 611-627.

Yanai, M., and T. Tomita, 1998: Seasonal and interannual variability of atmospheric heat sources and moisture sinks as determined from NCEP-NCAR reanalysis. Journal of Climate, 11 (3), 463-482.
Zschenderlein, P., A. H. Fink, S. Pfahl, and H. Wernli, 2019: Processes determining heat waves across different European climates. Quarterly Journal of the Royal Meteorological Society, 145 (724), 2973-2989.

Zschenderlein, P., S. Pfahl, H. Wernli, and A. H. Fink, 2020: A Lagrangian analysis of upper-tropospheric anticyclones associated with heat waves in Europe. Weather and Climate Dynamics, 1 (1), 191206. 


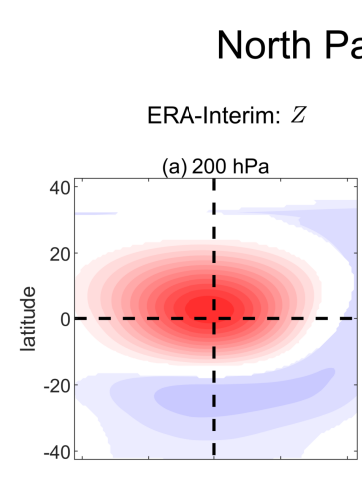

\section{ic: Winter}
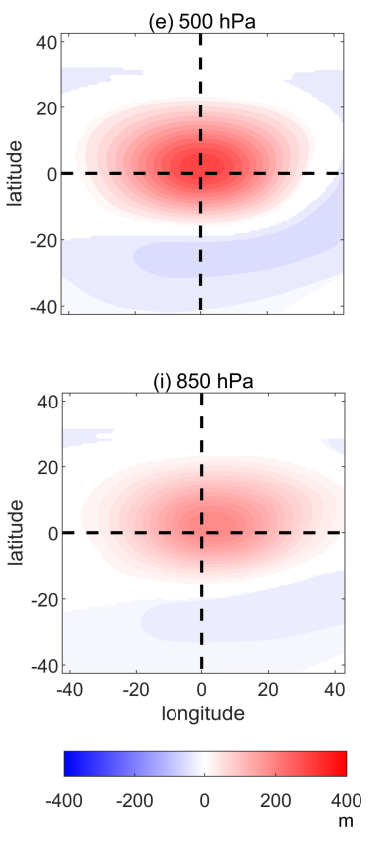

ERA-Interim: $v$
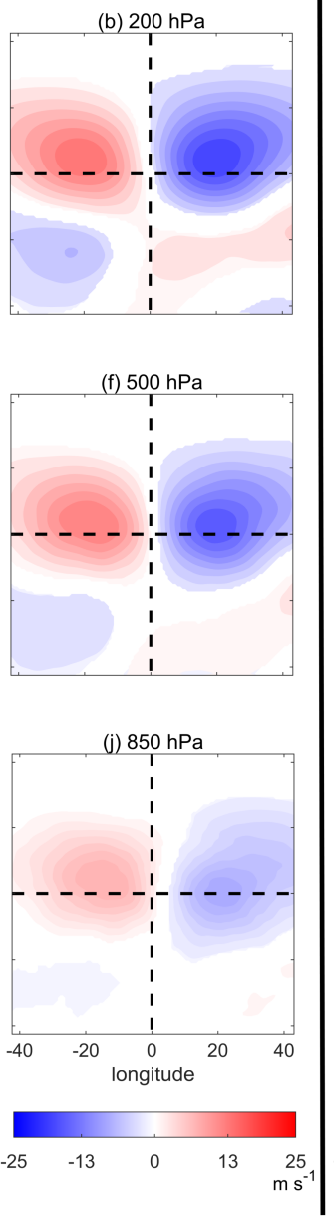

\section{North Pacific: Summer}

ERA-Interim: $Z$
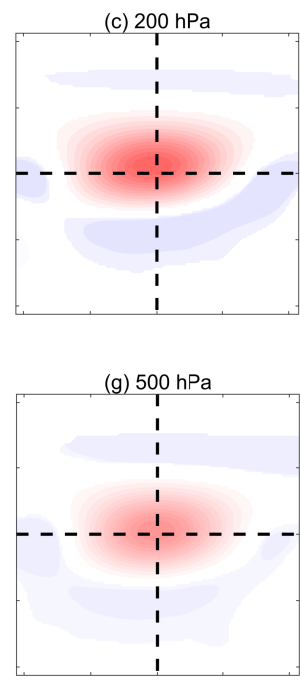

(k) $850 \mathrm{hPa}$

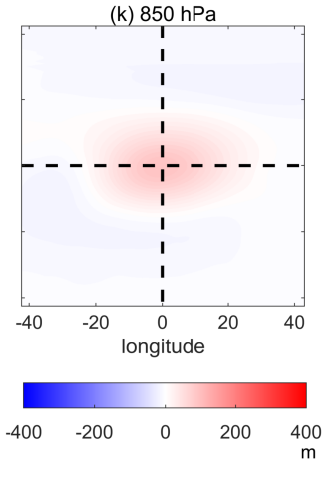

ERA-Interim: $v$
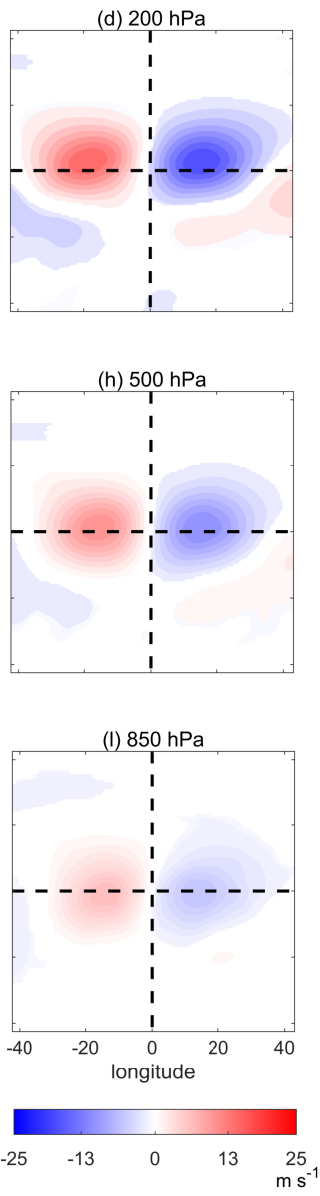

FIG. 1. Climatology of geopotential height $(Z)$ and meridional wind $(v)$ of blocking events in the ERA-Interim reanalysis over the North Pacific sector. Rows show $200 \mathrm{hPa}$ (top), $500 \mathrm{hPa}$ (middle), and $850 \mathrm{hPa}$ (bottom) levels. The two columns on the left are for winter (DJF) blocks while the two columns on the right are for summer (JJA) blocks. In all panels, anomalies are first centered in and then composited. The intersection of the dashed lines shows the center, and the latitudes and longitudes are relative to the center. All shown anomalies are significant at $95 \%$ level based on a one-sample $t$ test. 
North Pacific: Winter

ERA-Interim: $T$

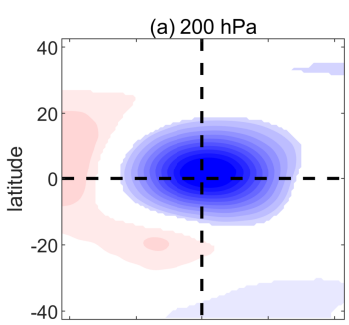

(d) $500 \mathrm{hPa}$

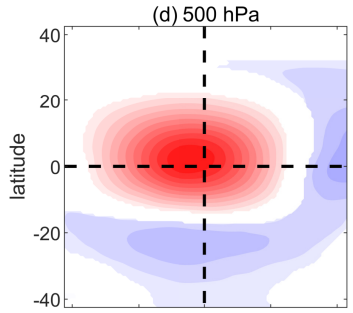

(h) $850 \mathrm{hPa}$

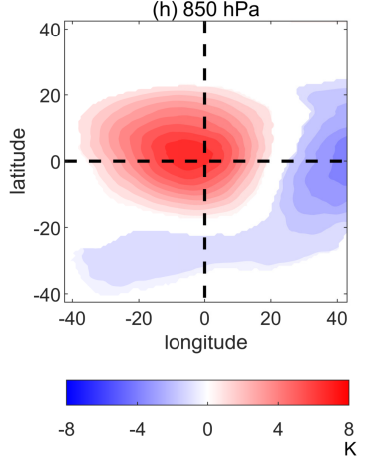

ERA-Interim: $\omega$

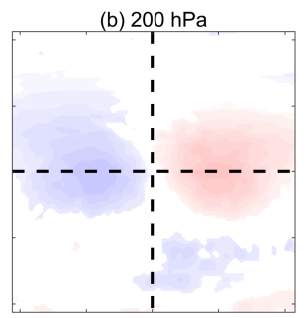

(e) $500 \mathrm{hPa}$

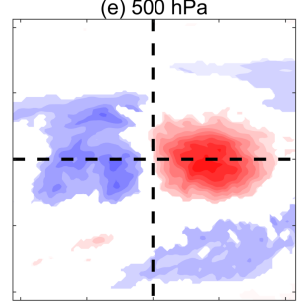

(i) $850 \mathrm{hPa}$
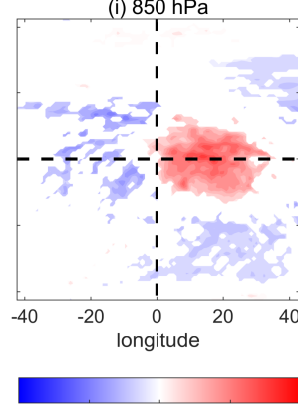

ERA-Interim: $S P$
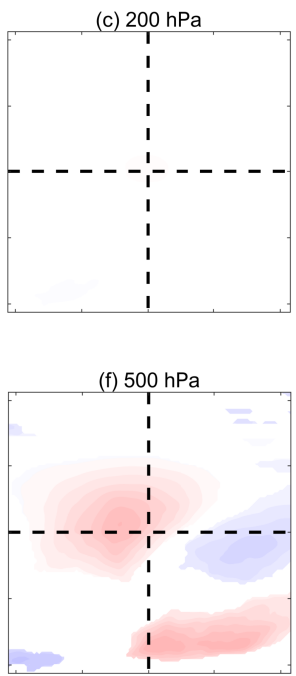

(j) $850 \mathrm{hPa}$
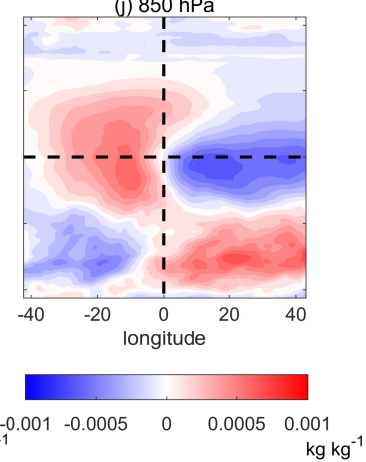

FIG. 2. Climatology of temperature $(T)$, vertical wind $(\omega)$, and specific humidity $(S P)$ of blocking events in the ERA-Interim reanalysis over the North Pacific sector during winters (DJF). Rows show $200 \mathrm{hPa}$ (top), $500 \mathrm{hPa}$ (middle), and $850 \mathrm{hPa}$ (bottom) levels. Columns show $T$ (left), $\omega$ (middle), and $S P$ (right). In all panels, anomalies are first centered and then composited. The intersection of the dashed lines shows the center, and the latitudes and longitudes are relative to the center. All shown anomalies are significant at $95 \%$ level based on a one-sample $t$ test. 


\section{North Pacific: Summer}

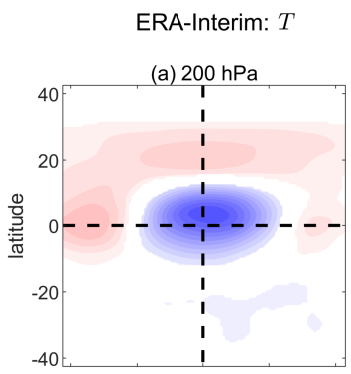

ERA-Interim: $\omega$
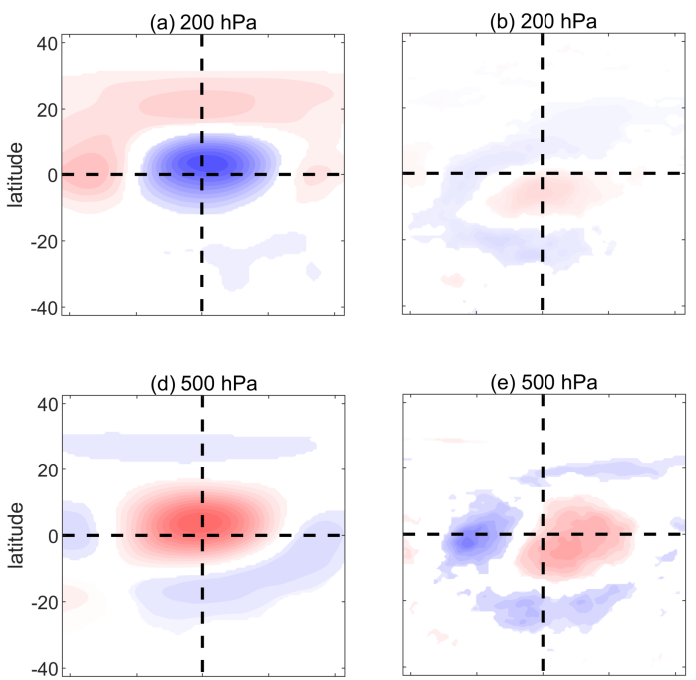

(h) $850 \mathrm{hPa}$

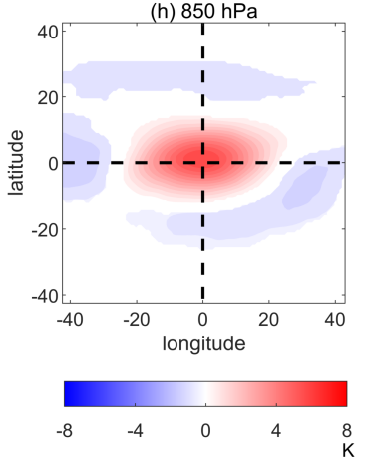

(e) $500 \mathrm{hPa}$

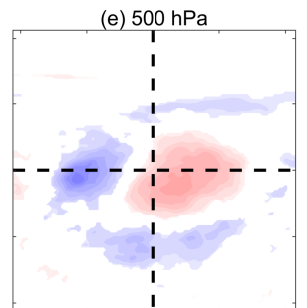

(i) $850 \mathrm{hPa}$
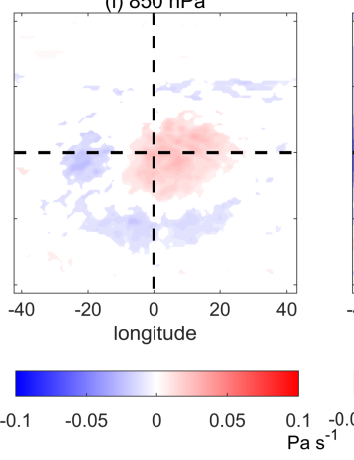

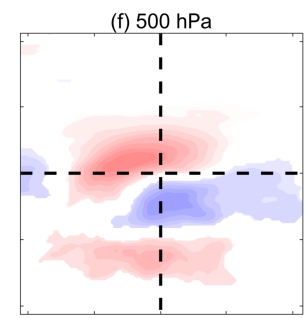

ERA-Interim: $S P$

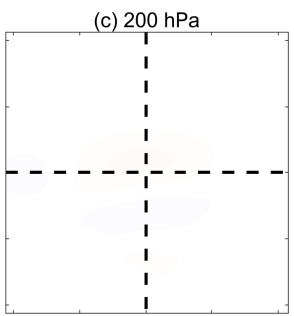

(j) $850 \mathrm{hPa}$
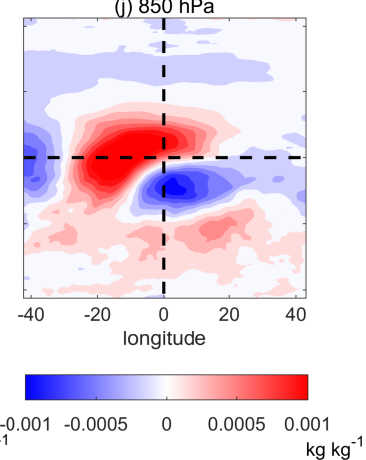

FIG. 3. The same as Fig. 2 but for summers (JJA). 
North Pacific: Winter
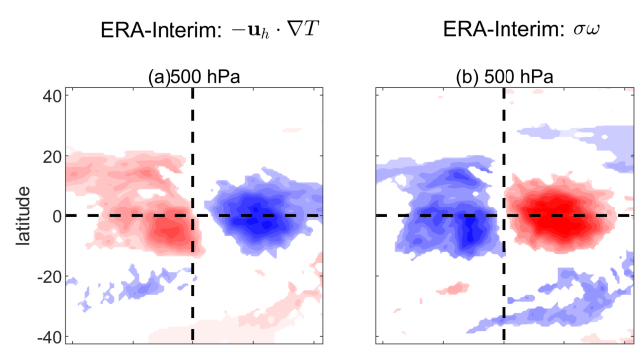

ERA-Interim: $-\mathbf{u}_{h} \cdot \nabla T+\sigma \omega$
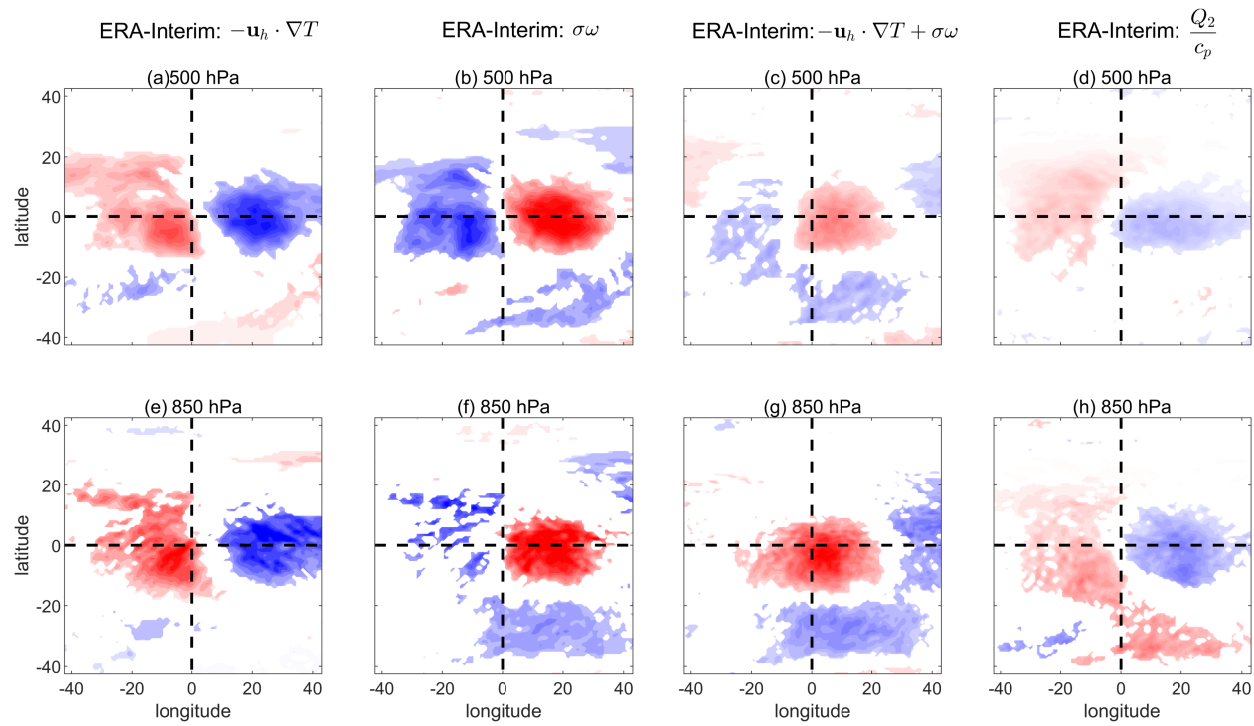

\section{Russia: Winter}
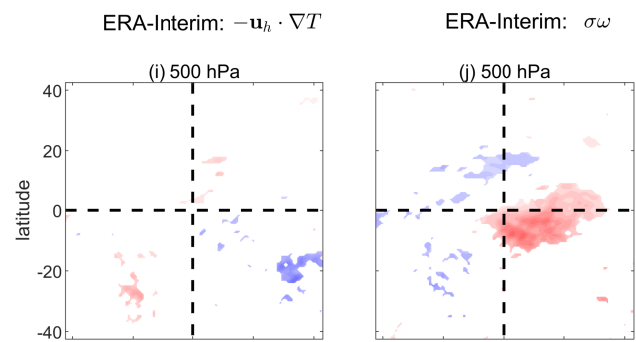

ERA-Interim: $-\mathbf{u}_{h} \cdot \nabla T+\sigma \omega$
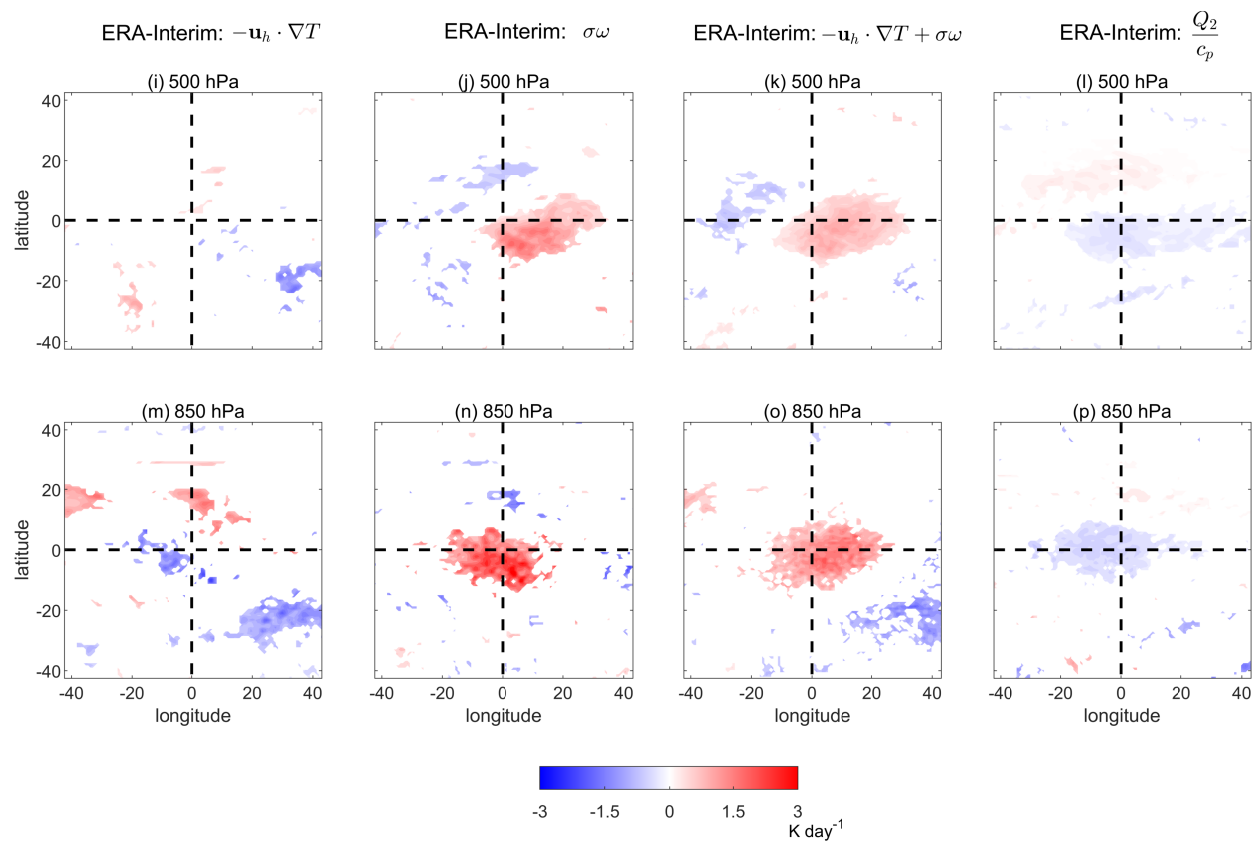

FIG. 4. Climatology of wintertime horizontal and vertical components of adiabatic warming (the first two columns from left), total adiabatic warming (third column), and latent heating (fourth column) over the North Pacific and Russia in the ERA-Interim reanalysis. All shown anomalies are significant at $95 \%$ level based on a one-sample $t$ test. The maximum amplitude of total adiabatic warming over North Pacific is $1.68 \mathrm{~K}^{-1}{ }^{-1}$ $(500 \mathrm{hPa})$ and $3.32 \mathrm{~K} \mathrm{day}^{-1}(850 \mathrm{hPa})$ and over Russia is $1.34 \mathrm{~K}^{-1 a y}{ }^{-1}(500 \mathrm{hPa})$ and $2.2 \mathrm{~K} \mathrm{day}^{-1}(850 \mathrm{hPa})$. The maximum amplitude of cooling due to $Q_{2}$ over North Pacific is $-0.86 \mathrm{~K} \mathrm{day}^{-1}(500 \mathrm{hPa})$ and $-1.62 \mathrm{~K} \mathrm{day}^{-1}(850 \mathrm{hPa})$ and over Russia is $-0.69 \mathrm{~K} \mathrm{day}{ }^{-1}(500 \mathrm{hPa})$ and $-1.68 \mathrm{~K}$ day $^{-1}(850 \mathrm{hPa})$. 
North Pacific: Summer
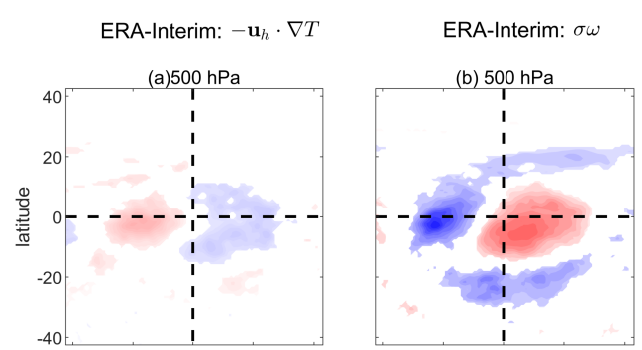

ERA-Interim: $-\mathbf{u}_{h} \cdot \nabla T+\sigma \omega$
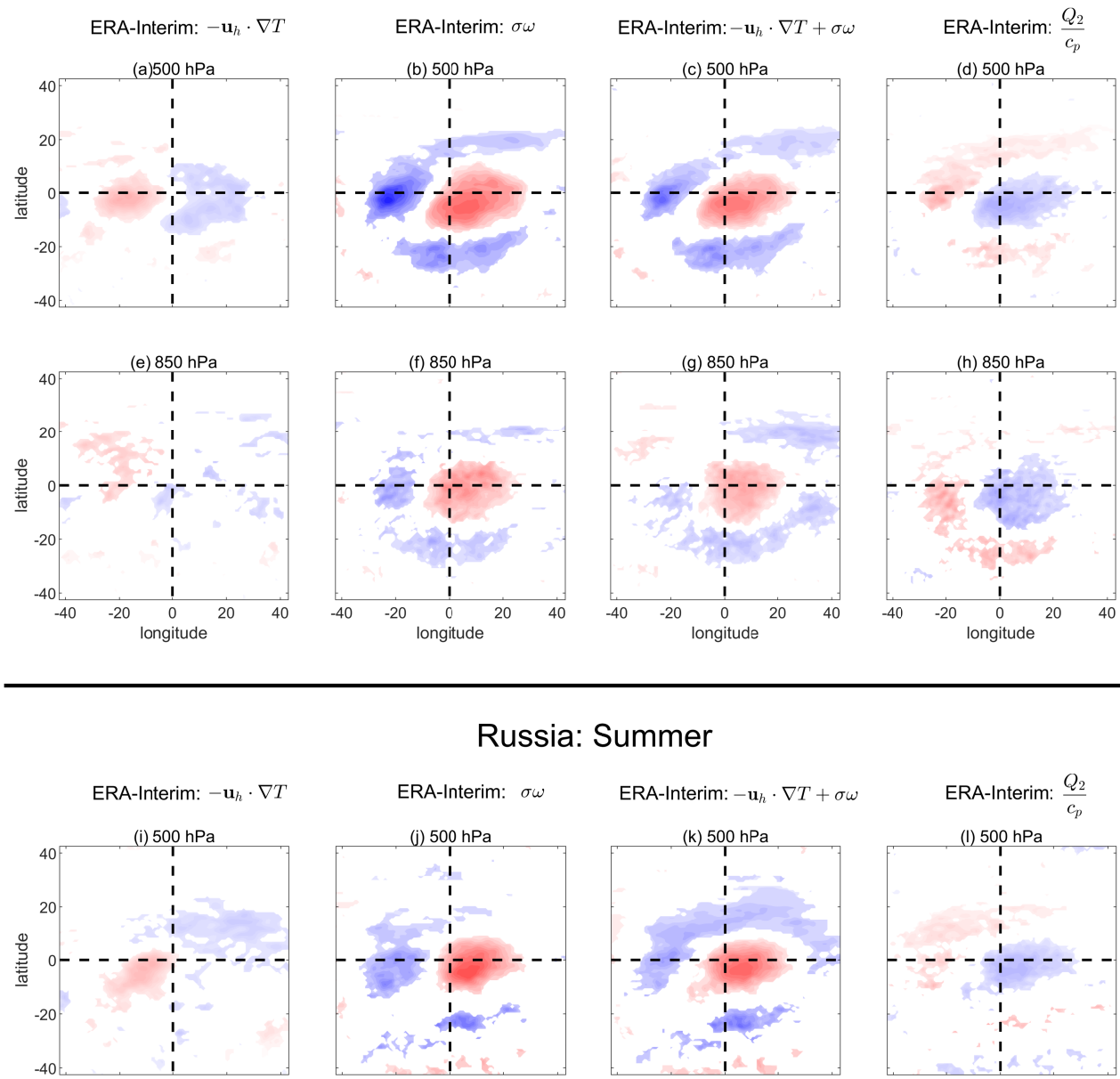

Russia: Summer
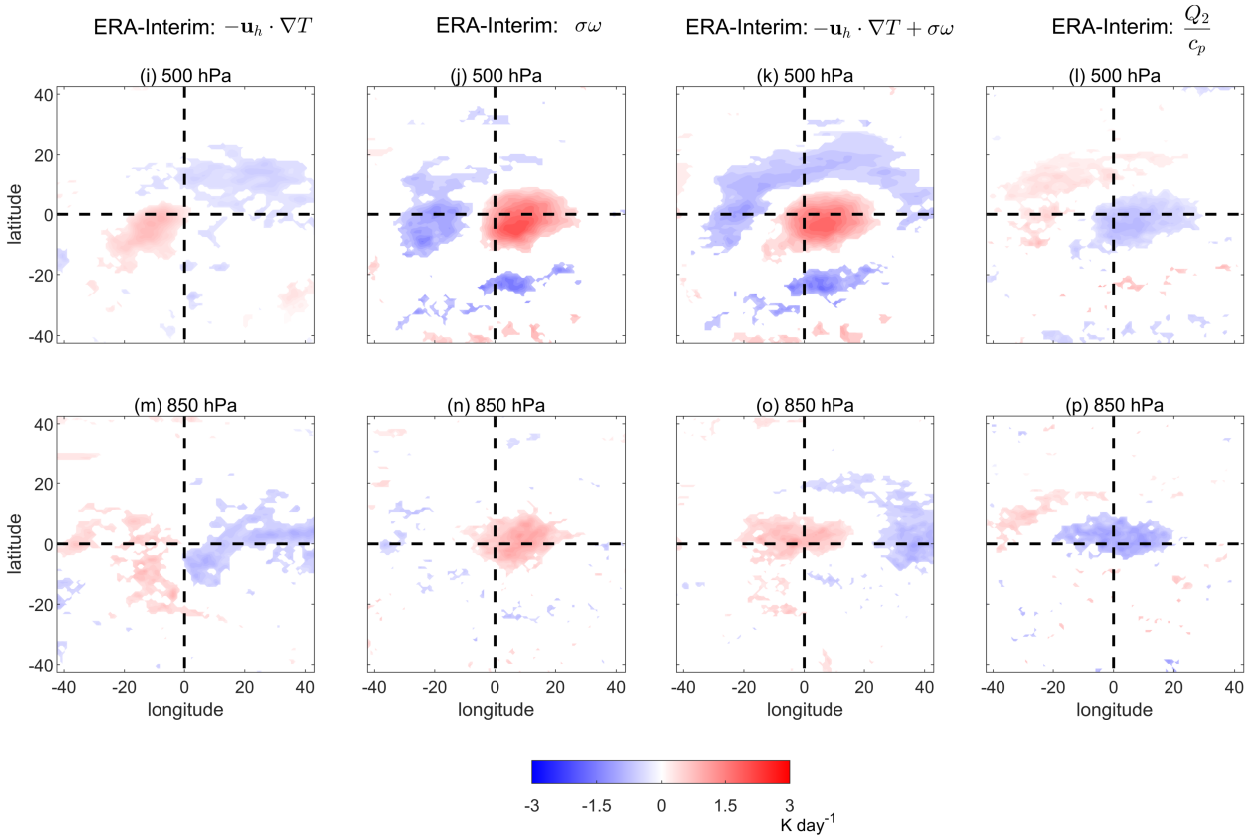

FIG. 5. Climatology of summertime horizontal and vertical components of adiabatic warming (the first two columns from left), total adiabatic warming (third column), and latent heating (fourth column) over the North Pacific and Russia in the ERA-Interim reanalysis. All shown anomalies are significant at $95 \%$ level based on a one-sample $t$ test. The maximum amplitude of total adiabatic warming over North Pacific is $1.69 \mathrm{~K}^{-1}{ }^{-1}$ $(500 \mathrm{hPa})$ and $1.15 \mathrm{~K} \mathrm{day}^{-1}(850 \mathrm{hPa})$ and over Russia is $1.94 \mathrm{~K}^{-1 a y}{ }^{-1}(500 \mathrm{hPa})$ and $1.20 \mathrm{~K} \mathrm{day}^{-1}(850 \mathrm{hPa})$. The maximum amplitude of cooling due to $Q_{2}$ over North Pacific is $-0.90 \mathrm{~K} \mathrm{day}^{-1}(500 \mathrm{hPa})$ and $-1.02 \mathrm{~K} \mathrm{day}^{-1}(850 \mathrm{hPa})$ and over Russia is $-0.80 \mathrm{~K} \mathrm{day}{ }^{-1}(500 \mathrm{hPa})$ and $-1.22 \mathrm{~K}$ day $^{-1}(850 \mathrm{hPa})$. 
North Pacific: Winter

LENS: $Z$

LENS: $v$

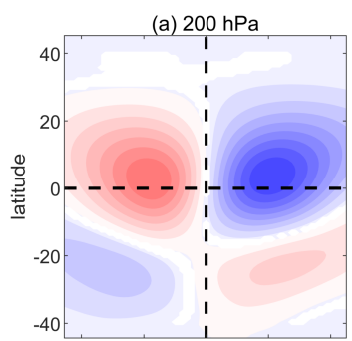

(e) $500 \mathrm{hPa}$
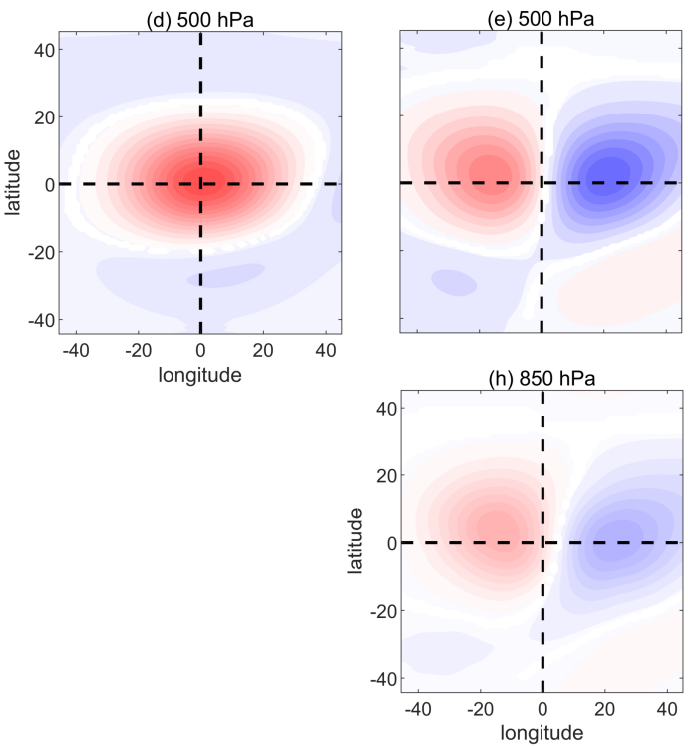

LENS: $T$
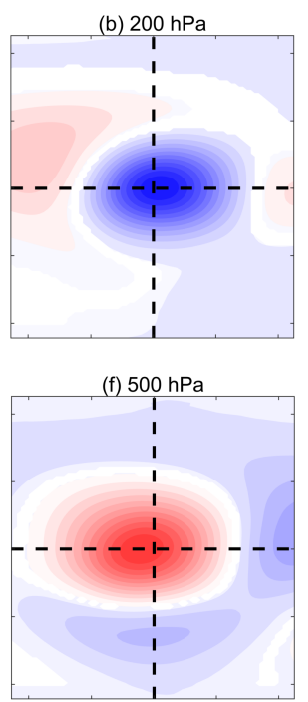

(i) $850 \mathrm{hPa}$
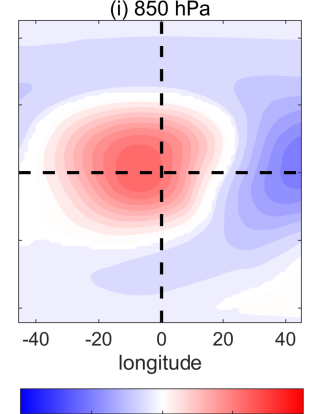

LENS: $S P$

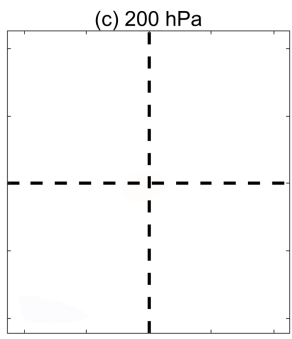

(g) $500 \mathrm{hPa}$

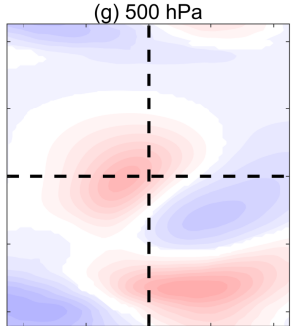

(j) $850 \mathrm{hPa}$

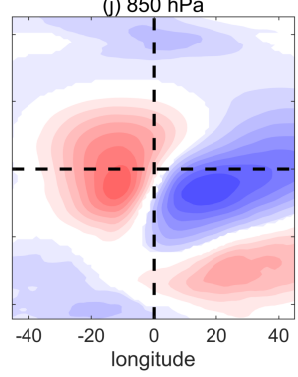

$\begin{array}{lllll}0.001 & -0.0005 & 0 & 0.0005 & 0.001\end{array}$ $\mathrm{m} \mathrm{s}^{-1}$ $\mathrm{kg} \mathrm{kg}$

FIG. 6. Climatology of $Z 500$, meridional wind ( $v$ ), temperature $T$, and specific humidity $S P$ of wintertime (DJF) blocking events in LENS over the North Pacific sector from 1981-2005. Rows show $200 \mathrm{hPa}$ (top), $500 \mathrm{hPa}$ (middle), and $850 \mathrm{hPa}$ (bottom) levels. Daily Z200 and Z850 are not available in the LENS dataset. In all panels, anomalies are first centered in and then composited. The intersection of the dashed lines shows the center, and the latitudes and longitudes are relative to the center. All shown anomalies are significant at $95 \%$ level based on a one-sample $t$ test. 


\section{North Pacific: Summer}

LENS: $Z$

LENS: $v$

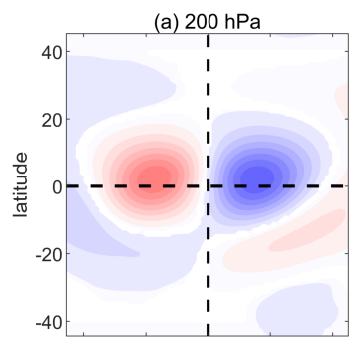

(e) $500 \mathrm{hPa}$
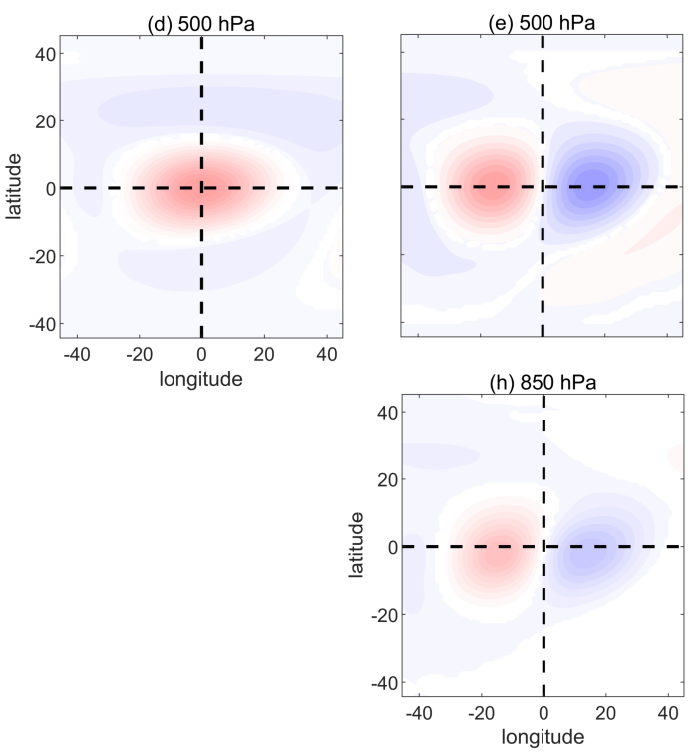

LENS: $T$

(b) $200 \mathrm{hPa}$

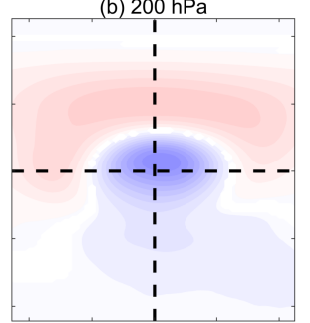

(f) $500 \mathrm{hPa}$

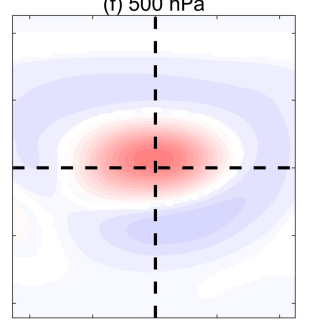

(i) $850 \mathrm{hPa}$
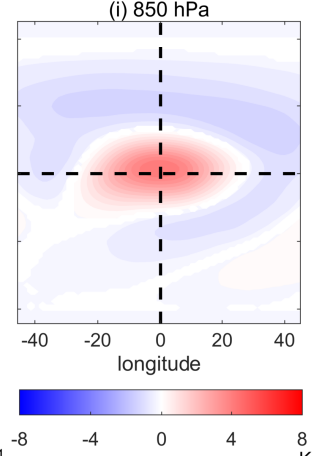

LENS: $S P$

(c) $200 \mathrm{hPa}$

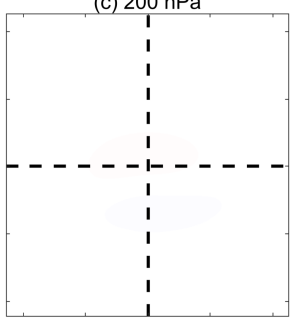

(g) $500 \mathrm{hPa}$

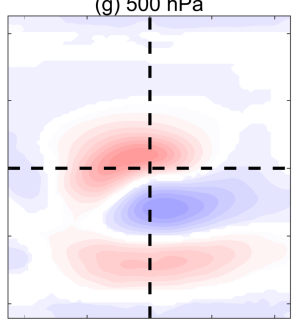

(j) $850 \mathrm{hPa}$

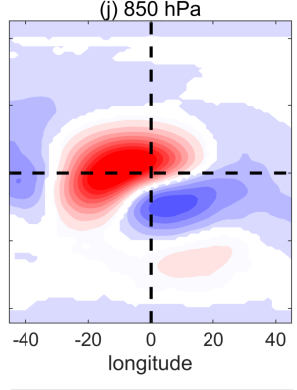

$\begin{array}{ccccc}-0.001 & -0.0005 & 0 & 0.0005 & 0.001\end{array}$

FIG. 7. The same as Fig. 6 but for summers (JJA). 


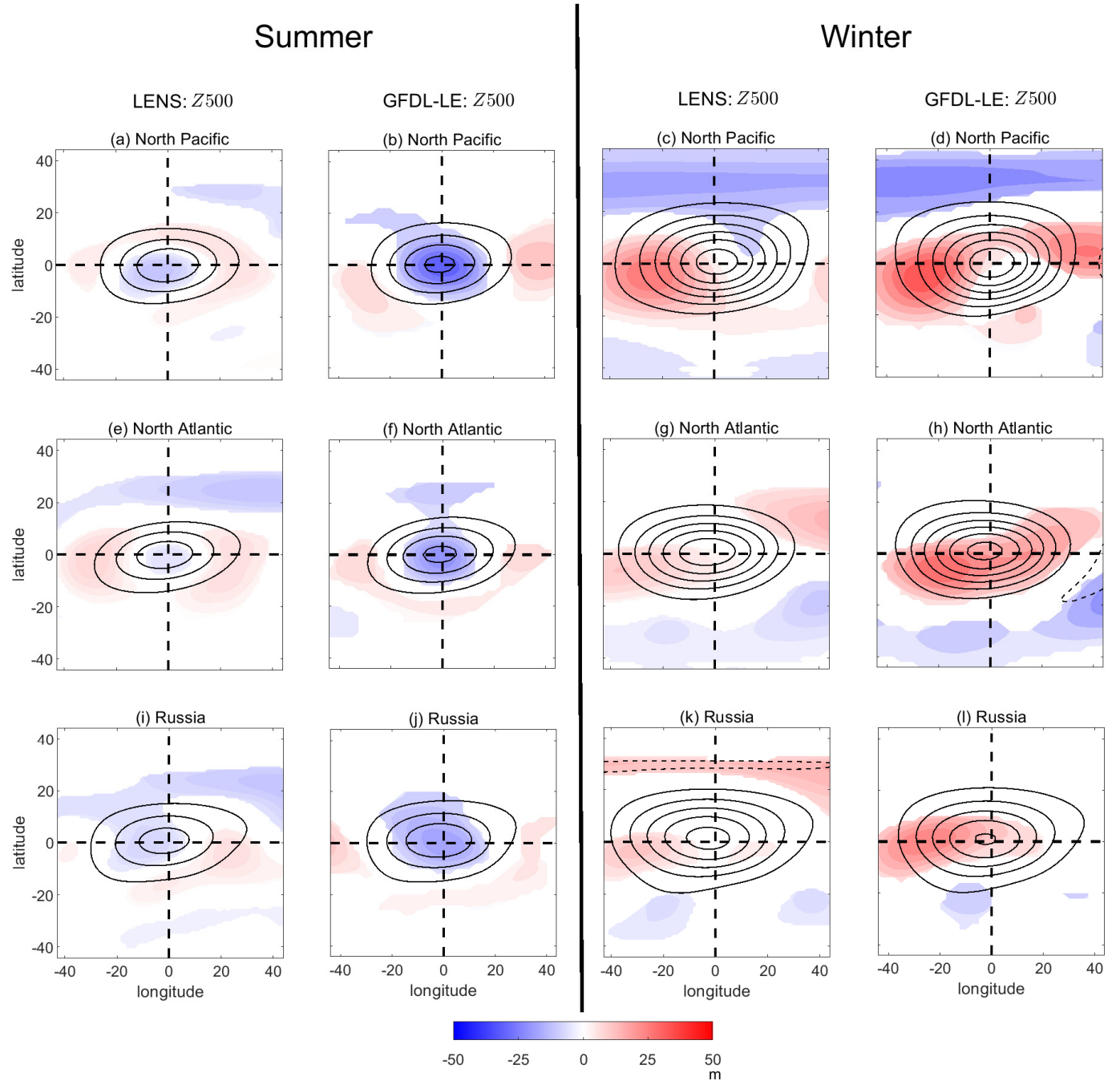

FIG. 8. Response of the blocking evens' Z500 in summer (JJA), left columns, and winter (DJF), right columns, in the LENS and GFDL-LE datasets. (a)-(d): North Pacific sector, (e)-(h): North Atlantic sector, and (i)-(1): Russian sector. All shown anomalies are significant at 95\% level based on a two-tailed $t$ test. Contourlines represent the climatology of Z500 anomalies with the interval of $50 \mathrm{~m}$. 


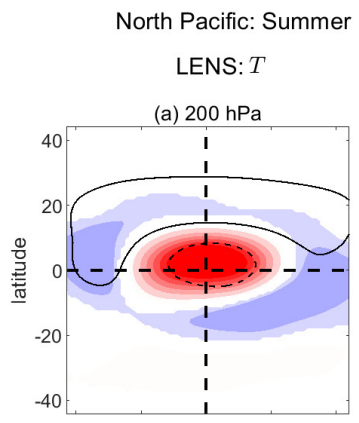

\section{North Atlantic: Summer}

LENS: $T$
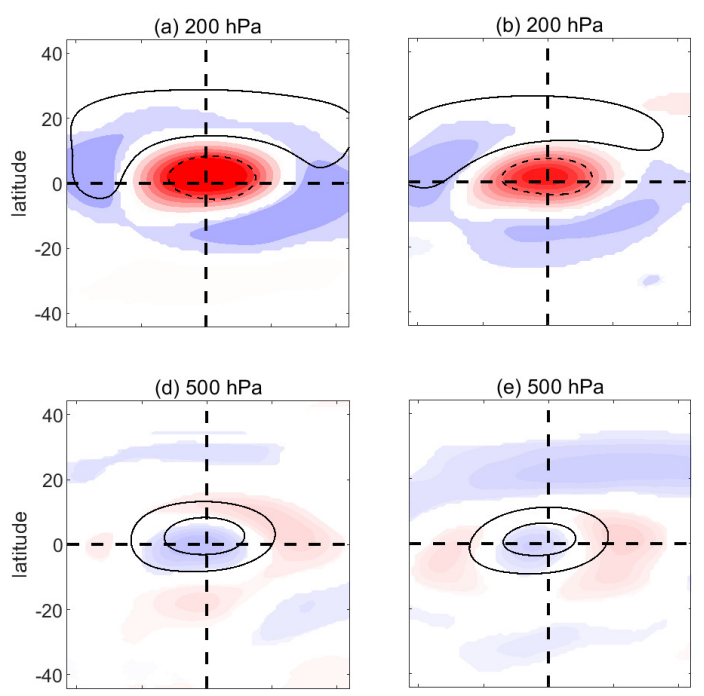

(g) $850 \mathrm{hPa}$

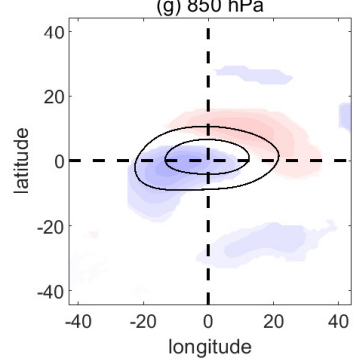

(e) $500 \mathrm{hPa}$

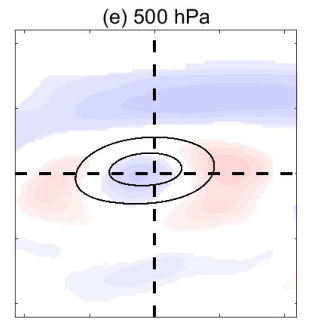

(h) $850 \mathrm{hPa}$

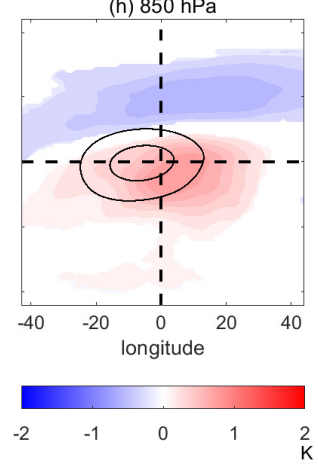

Russia: Summer

LENS: $T$

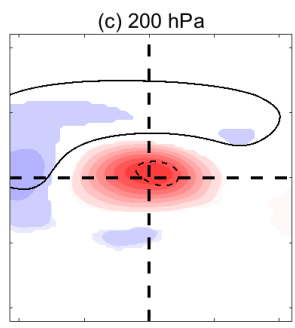

(f) $500 \mathrm{hPa}$

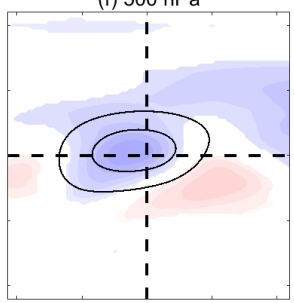

(i) $850 \mathrm{hPa}$

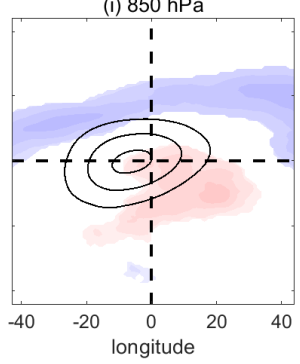

FIG. 9. Response of summertime (JJA) temperature $T$ associated with blocking events in the LENS dataset. Rows 1-3 show, respectively, the $200 \mathrm{hPa}, 500 \mathrm{hPa}$, and $850 \mathrm{hPa}$ levels. Columns 1-3 show, respectively, the North Pacific, North Atlantic, and Russian sectors. All shown anomalies are significant at $95 \%$ level based on a two-tailed $t$ test. Contourlines represent the climatology of $T$ anomalies with the interval of $2 \mathrm{~K}$. 


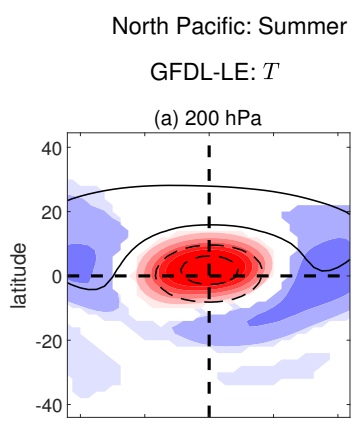

North Atlantic: Summer

GFDL-LE: $T$

(b) $200 \mathrm{hPa}$

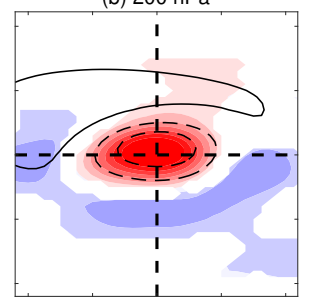

(e) $500 \mathrm{hPa}$

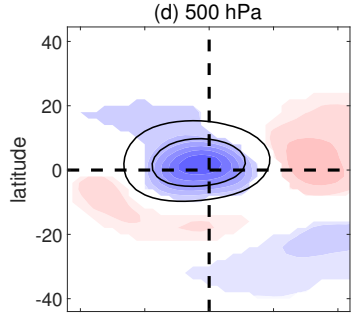

(g) $850 \mathrm{hPa}$
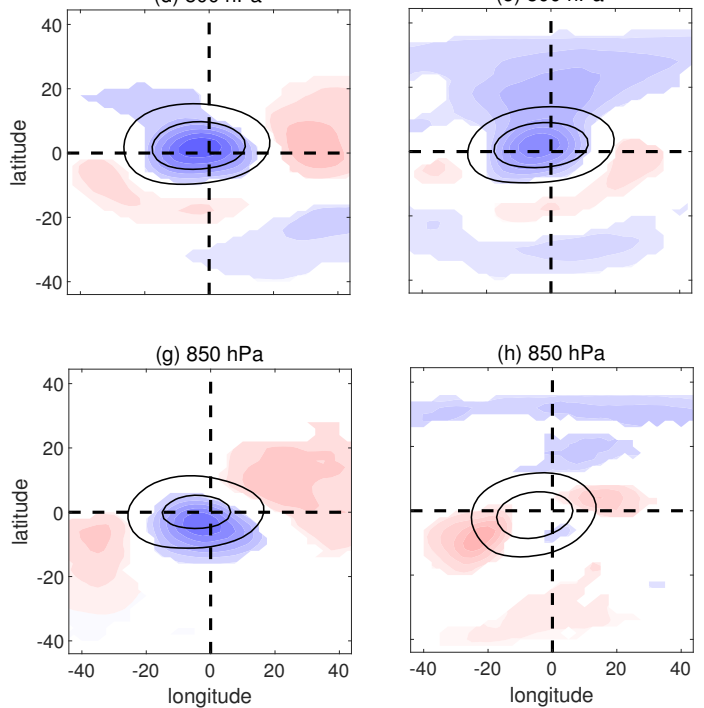

(h) $850 \mathrm{hPa}$
Russia: Summer

GFDL-LE: $T$

(c) $200 \mathrm{hPa}$
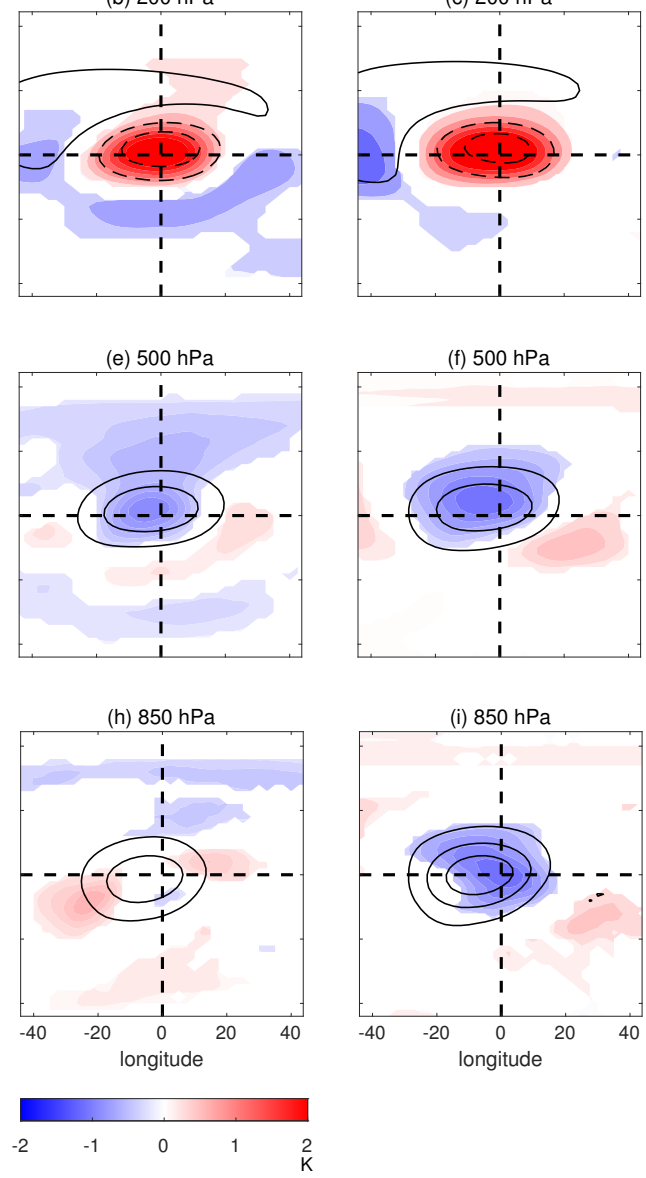

(f) $500 \mathrm{hPa}$

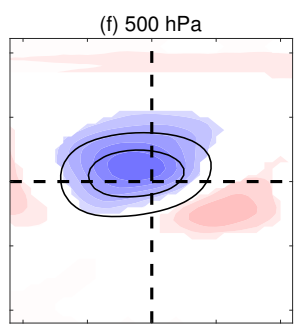

(i) $850 \mathrm{hPa}$

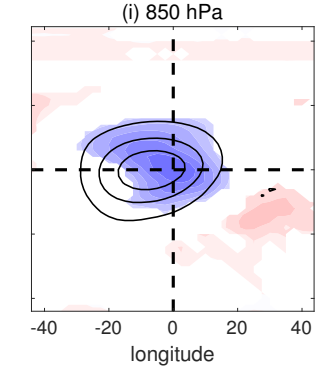

FIG. 10. The same as Fig. 9 but for the GFDL-LE dataset. 


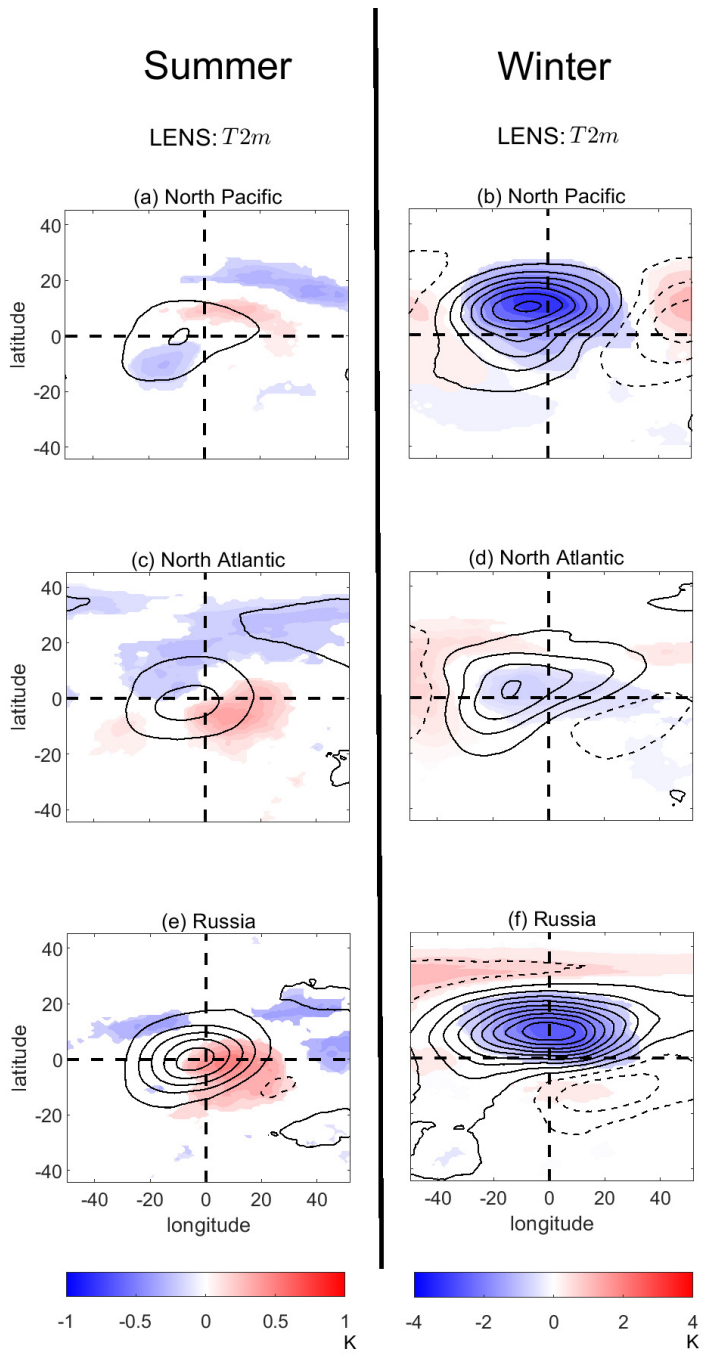

FIG. 11. Response of summertime (JJA) and wintertertime (DJF) near-surface surface temperature $T 2 m$ associated with blocking events in the LENS dataset. (a) (c), and (e): Summers; (b), (d), and (f): winters. Rows 1-3 show, respectively, the North Pacific, North Atlantic, and Russian sectors. All shown anomalies are significant at $95 \%$ level based on a two-tailed $t$ test. Contourlines represent the climatology of $T 2 m$ anomalies with the interval of $1 \mathrm{~K}$. 


\section{Summer}

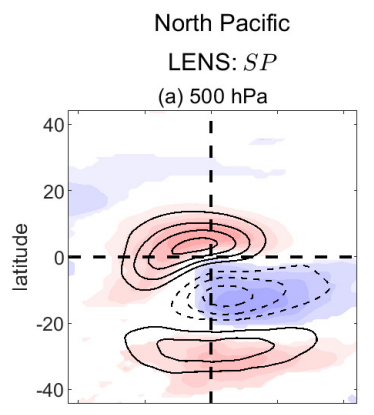

North Atlantic

LENS: $S P$
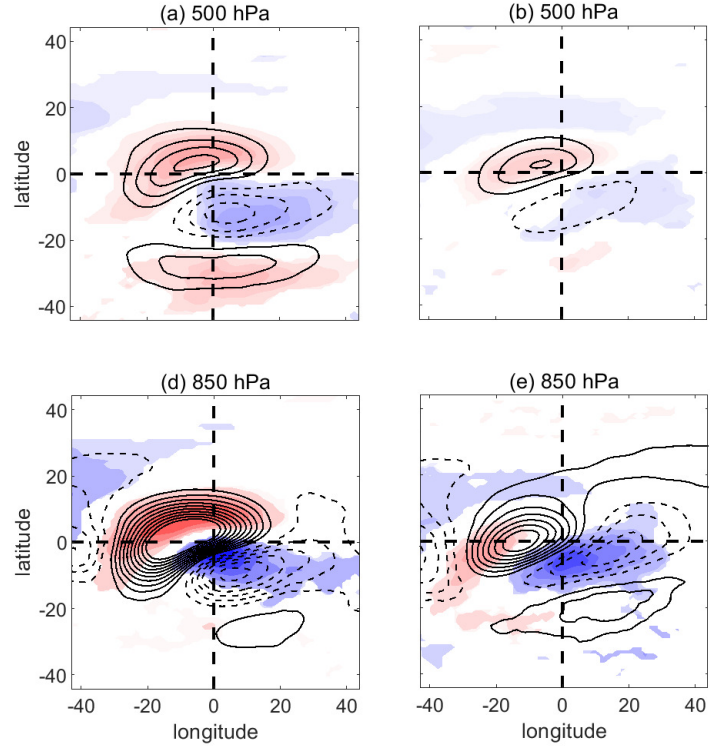

(e) $850 \mathrm{hPa}$

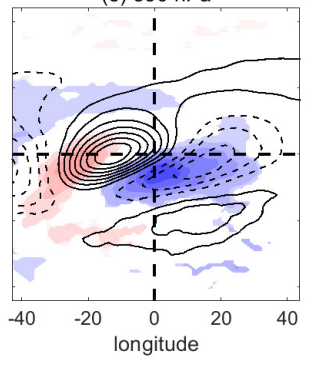

Russia

LENS: $S P$

(c) $500 \mathrm{hPa}$

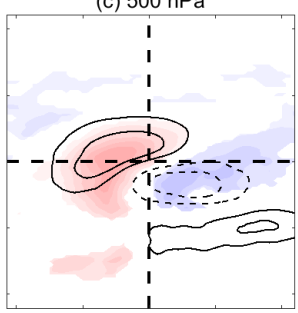

(f) $850 \mathrm{hPa}$

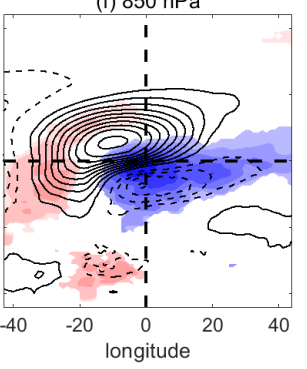

Winter

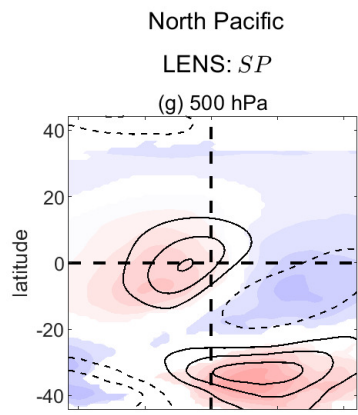

North Atlantic

LENS: $S P$

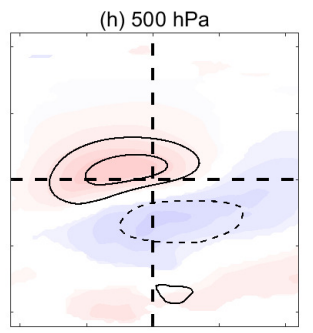

Russia

LENS: $S P$
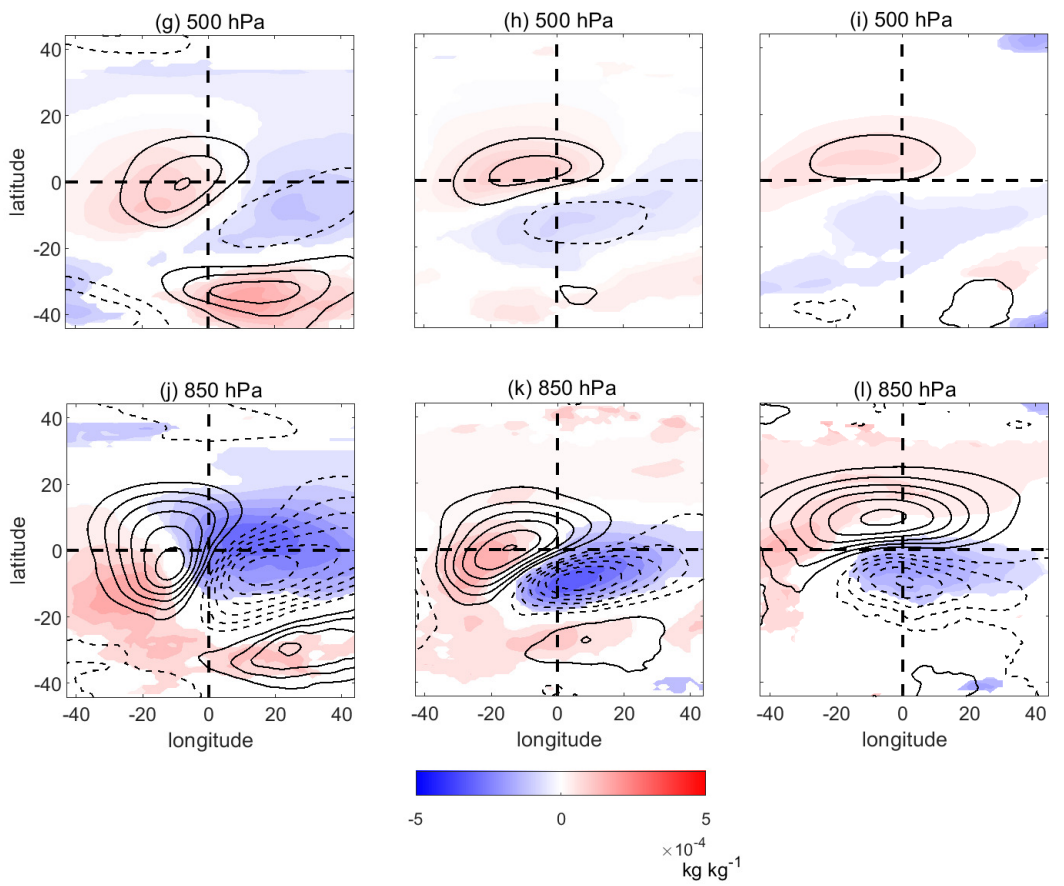

FIG. 12. Response of summertime (JJA) and wintertertime (DJF) specific humidify $S P$ associated with blocking events in the LENS dataset. (a)-(f): Summers; (g)-(1): Winters. Rows 1 and 3 (2 and 4) show the results at $500 \mathrm{hPa}(850 \mathrm{hPa})$. Columns 1-3 show, respectively, the North Pacific, North Atlantic, and Russian sectors. All shown anomalies are significant at $95 \%$ level based on a two-tailed $t$ test. Contourlines represent the climatology of $S P$ anomalies with the interval of $10^{-5} \mathrm{~kg} \mathrm{~kg}^{-1}$. 


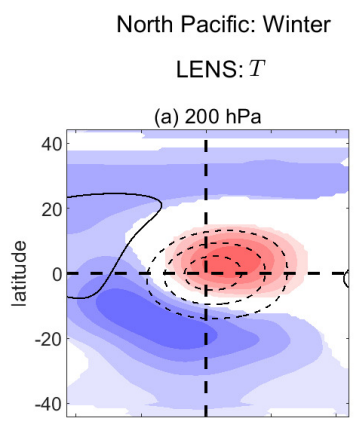

\section{North Atlantic: Winter}

LENS: $T$
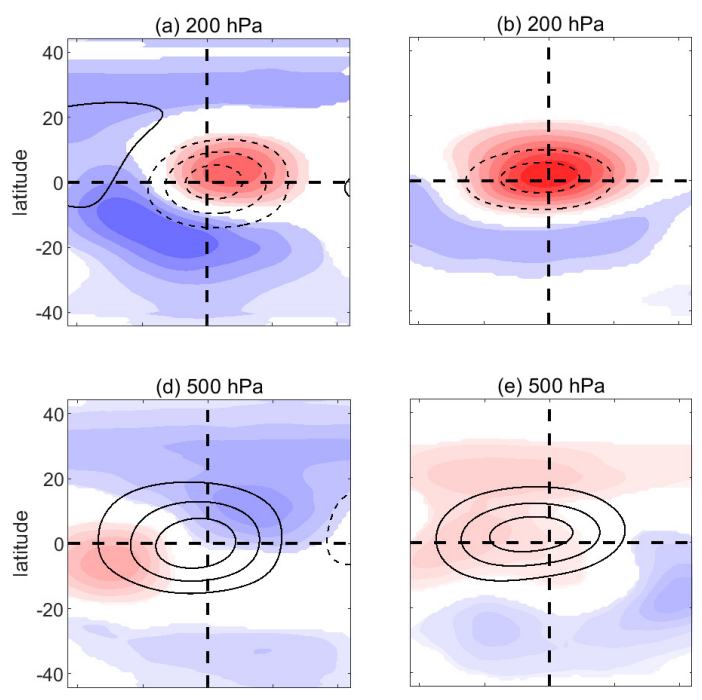

(g) $850 \mathrm{hPa}$

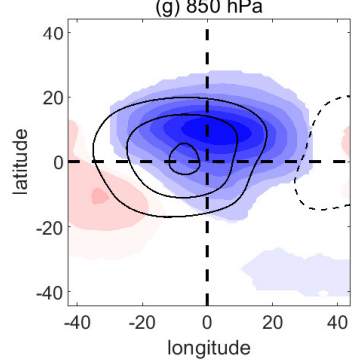

(e) $500 \mathrm{hPa}$

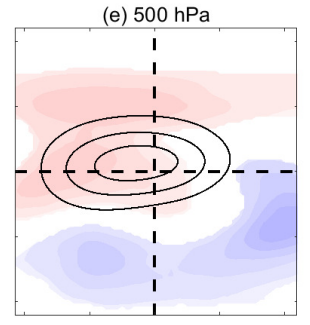

(h) $850 \mathrm{hPa}$

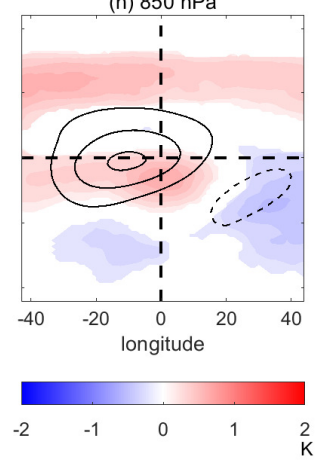

Russia: Winter

LENS: $T$

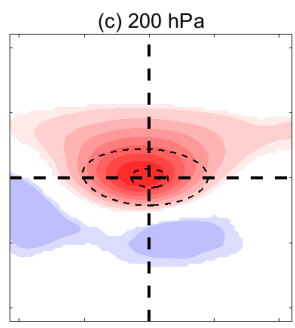

(f) $500 \mathrm{hPa}$

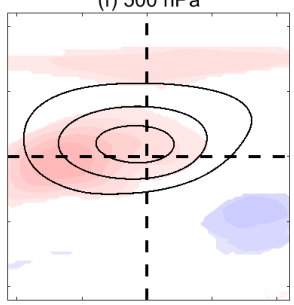

(i) $850 \mathrm{hPa}$

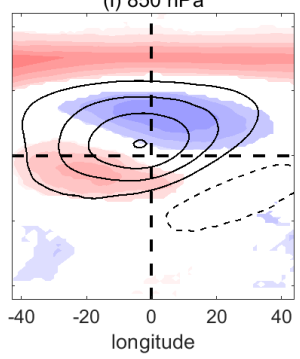

FIG. 13. Response of wintertime (DJF) temperature $T$ associated with blocking events in the LENS dataset. Rows $1-3$ show, respectively, the $200 \mathrm{hPa}, 500 \mathrm{hPa}$, and $850 \mathrm{hPa}$ levels. Columns 1-3 show, respectively, the North Pacific, North Atlantic, and Russian sectors. All shown anomalies are significant at $95 \%$ level based on a two-tailed $t$ test. Contourlines represent the climatology of $T$ anomalies with the interval of $2 \mathrm{~K}$. 

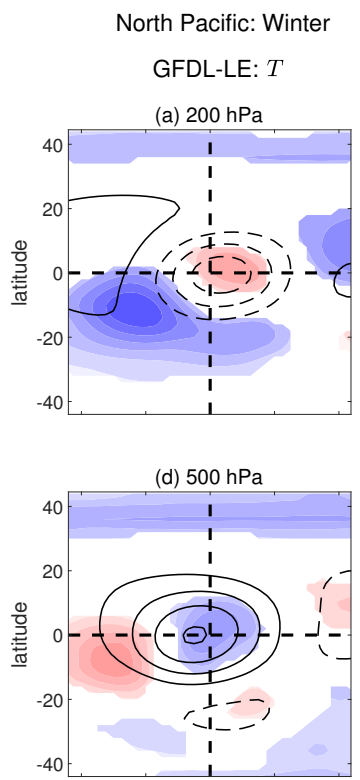

(g) $850 \mathrm{hPa}$

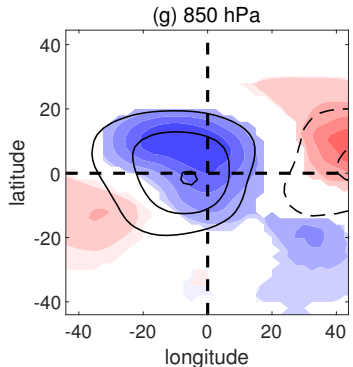

North Atlantic: Winter

GFDL-LE: $T$

(b) $200 \mathrm{hPa}$

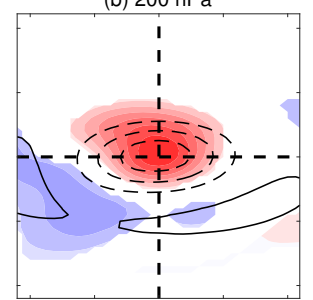

(e) $500 \mathrm{hPa}$

Russia: Winter

GFDL-LE: $T$

(c) $200 \mathrm{hPa}$

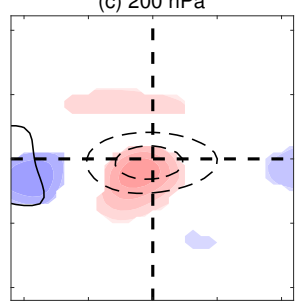

(f) $500 \mathrm{hPa}$

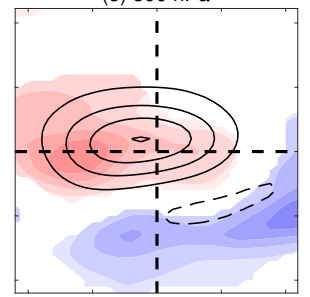

(h) $850 \mathrm{hPa}$

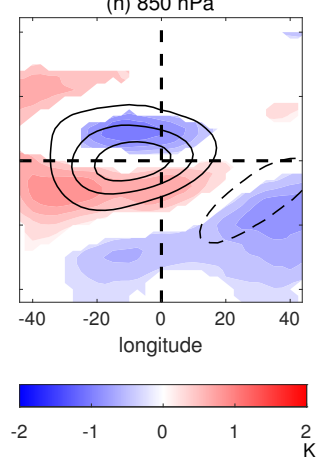

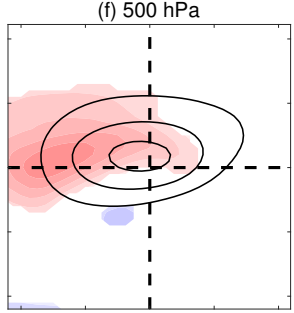

(i) $850 \mathrm{hPa}$

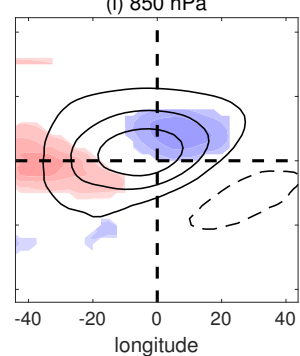

FIG. 14. The same as Fig. 13 but for the GFDL-LE dataset. 